\title{
Self-defining Memories - Narrative Features in Relation to Adaptive and Maladaptive Personality Traits (Replication and Extension of Blagov \& Singer, 2004)
}

\section{A peer-reviewed version of this manuscript is in print in Journal of Personality.}

\section{Version 6.0}

This manuscript was previously titled "Self-defining Memories (Their Affect, Structure, Meaning, and Content) in Relation to Temperament, Trait Domains, and Psychological Adjustment). The version of the manuscript herein preceded the completion of the peer-review process. The peerreviewed, edited, and published version of this manuscript appears in Journal of Personality at https://doi.org/10.1111/jopy.12677.

\author{
Pavel S. Blagov, PhD \\ Whitman College \\ Jefferson A. Singer, PhD \\ Connecticut College \\ Kathryn M. Oost, PhD \\ Whitman College \\ Joshua A. Goodman, PhD \\ Rhodes College
}

2021

\section{Author notes:}

Correspondence: blagovp@whitman.edu; 345 Boyer Ave., Walla Walla, WA 99362

Data: http://dx.doi.org/10.17632/jv68zhz58s.2

Funding: The authors received no external financial support.

Disclosure: The authors declare no potential conflicts of interest.

Ethics: This research complies with federal, institutional, and professional ethics guidelines.

Preregistration: Planned prior to the replication crisis, this research was not preregistered. 


\begin{abstract}
Self-defining memories (SDMs) are units of life-story analysis, whose features resemble elements from narrative identity's factorial structure. To bridge narrative-identity and personality-trait domains, we conducted a replication and extension of Blagov and Singer's (2004) research in a small sample that was well-powered for multilevel modeling (133 participants, 1330 SDMs). We linked four SDM features - affect, specificity, meaning making, and content - to the Big Three trait domains of personality and psychopathology, finding support for several claims. Affect: SDM affect correlated with indices of Positive Emotionality and Negative Emotionality, and narrative themes of contamination were associated with Negative Emotionality. Specificity: SDM specificity vs. overgenerality related to Constraint and Negative Emotionality indices, lending support to the executive dysfunction and emotional disorder theories of overgeneral autobiographical memory. (Tests of the avoidance thesis of overgeneral memory were inconclusive.) Meaning making: Explicit meaning making in SDMs reflected adaptive personality. It moderated the link between SDMs' affect and chronic emotional distress. Content: The links between SDM content and traits suggest that SDMs reflect personal goals, whose fulfillment or frustration relate to psychological health. This research serves replication purposes as well as the purpose of connecting two major domains of personality: narrative identity and adaptive and maladaptive traits.
\end{abstract}

\title{
Keywords:
}

Autobiographical memory, self-defining memories, narrative identity, five-factor model, the Big Three, personality traits, meaning making 


\section{Self-defining Memories - Narrative Features in Relation to Adaptive and Maladaptive Personality Traits (Replication and Extension of Blagov \& Singer, 2004)}

Self-defining memories (SDMs) are autobiographical memories (AMs) elicited using a specific prompt and used often in research on narrative identity (Singer et al., 2013; Adler et al., 2017). In a frequently cited study, Blagov and Singer (2004) reviewed four types of SDM features and linked them to trait-like personality dimensions. Here, we revisit this research for three reasons. First, it was important that we attempt to replicate it. Two more reasons relate to recent advances in research on narrative-identity theory (McAdams, 2018).

Evidence has emerged for at least 3-4 key factors that underlie differences in the ways people construct the stories of their lives (McLean et al., 2020). Our article's second goal is to discuss how the features of SDMs relate to this emerging structural model of narrative identity.

Narrative identity seems to predict well-being over and above such personality constructs as traits (Adler et al., 2016). Given that traits comprise another major domain of personality and predict well-being, Adler and Clark (2019) recommended studying the links between the structures of narrative identity and traits pertaining to psychopathology. Our third goal was to link SDMs' narrative features to the Big Three trait domains (Markon et al., 2005) featured prominently in integrative models of personality and psychopathology (Sellbom et al., 2020).

Below, we first discuss the theoretical role of SDMs in narrative identity and summarize Blagov and Singer's (2004) study. We then explain the trait framework we adopted, and we comment on the resemblance between SDMs' features and certain narrative-identity factors.

\section{SDMs and Their Role in Narrative Identity}

How do SDMs fit within narrative-identity theory? According to the theory (McAdams, 2018), the life-story narrative, which a person constructs, recalls, revises, and shares with others, is essential to identity. It is thought to provide a sense of a self that has continuity, stability, and coherence over time, along with a sense of purpose. The life story emerges from AM through the use of developmentally acquired recall and reflection skills (Fivush, 2014). These skills include 
narrative processing, which organizes the self, events, plans, actions, and their likely outcomes into story-like units. Narrative processing includes meaning making (Habermas \& Bluck, 2000), whereby the person draws lessons from AMs about the self, relationships, or life. We see SDMs as salient AMs that result from narrative processing and often involve meaning making. They exist in a reciprocal relationship with the life story (Singer \& Blagov, 2004; Singer et al., 2013), informing and informed by it, and often becoming its touchstones.

An SDM is, by definition, subjectively clear and important, recurrent, enduring (at least a year old), connected to similar memories, and relevant to long-standing issues in the person's life. Prior to being asked to write down their SDMs, research participants read the SDM prompt, which introduces them to these memories' defining attributes (see Supplementary Materials, Appendix $\mathrm{SA})$. As the SDM-eliciting prompt stresses these memories' enduring relevance and linkage to similar memories, narrative-identity researchers collect them when studying stability more so than transformation in people's life stories (Adler et al., 2017).

Research has confirmed that SDMs are, indeed, recurrent, highly self-relevant (Çili \& Stopa, 2014), and linked to enduring personal goals and concerns (Sutin \& Robins, 2005). To the person, they feel vivid, emotional, and important to their strivings, relationships, identity, or values (Luchetti et al., 2016). Therefore, SDMs often capture central or focal events in people' life stories and inform their narrative identities. If people's memories fall on a spectrum of centrality to their life stories, then SDMs appear in the high band of this spectrum.

SDMs are, then, a form of AMs that are necessary (but not sufficient) for a narrative identity. Hierarchically, they are a lower-order construct than the life story, and they link currently activated goals and self-representations to more abstract elements of the life story and the self as represented in long-term memory (Conway et al., 2004).

\section{The Original Study}

Having located SDMs within narrative-identity theory, we turn to Blagov and Singer's (2004) study. It focused on four types of narrative SDM features: affect, specificity, meaning, and content. 
Rationale. Blagov and Singer (2004) theorized that people differ in the degree to which they use AMs adaptively. This would translate into associations of SDM features with adaptive and maladaptive personality (see also Singer et al., 2013). AMs inform the person's pursuit, attainment, and revision of their goals (Conway et al., 2004), which is key for adaptation. Thus, AMs' content likely reflects motivation, and AMs' affect - the degree of mismatch between desired vs. perceived states of affairs (Singer, 1990). SDMs are especially informative about the self and often entail meaning making. This would facilitate the use of AMs to promote adaptation. Based on SDM theory and the literature, Blagov and Singer expected specificity (defined later), content about improved relationships or achievement successes, explicit meaning making, and positive affect to relate to adaptive personality. Low specificity, content about failures and worsening relationships, limited meaning making, and negative affect were thought to relate to maladaptive personality.

Findings. A modest sample of 103 undergraduates wrote down 10 SDMs each and completed a clinical-psychological measure of trait-like dimensions: distress, self-restraint, and defensiveness. Participants rated their SDMs' affect, and researchers coded the other SDM features. Distress was expected and found to correlate with SDMs' negative affect, positive affect (inversely), worsened relationship content, achievement success content (inversely), as well as with specific positive SDMs (also inversely). Distress was expected but not found to correlate positively with achievement failures, negatively with improved relationships, or negatively with specific SDMs. Self-restraint had the predicted curvilinear association with meaning making in SDMs, whereby moderate (presumably the healthiest) levels of self-restraint corresponded to higher numbers of SDMs with explicit meaning making. Finally, defensiveness was expected and found to correlate negatively with specific SDMs.

This was an early demonstration that selected narrative features correlate with trait-like dimensions pertinent to well-being. We will discuss the resemblance of the SDM features to facets from McLean et al.'s (2020) taxonomy, but first we must address our selection of trait variables. Selection of Trait Variables 
To link SDM features to traits that predict psychological health, we selected measures (see Table 1) that reflect the Big Three trait domains: Positive Emotionality, Negative Emotionality, and Constraint (Watson et al., 2006).

Why focus on the Big Three? Established models of normal traits include five- and threefactor models that reflect the same underlying trait structure as does much of psychopathology (Markon et al., 2005; Wright et al., 2012). The Big Three are especially well represented in modern models of personality traits and psychopathology (Markon et al., 2005; Sellbom et al., 2020). Positive Emotionality, Negative Emotionality, and Constraint correspond closely to extraversion, neuroticism, and conscientiousness in five-factor models. In terms of maladaptive traits, low Positive Emotionality corresponds to anhedonic detachment (Wright et al., 2012). With Negative Emotionality, it forms a predisposition to internalizing disorders (characterized primarily by mood, worry, and fear symptoms). Low Constraint corresponds to disinhibition and predisposes toward externalizing disorders (characterized by impulsive, behavioral, and addiction symptoms; Sellbom et al., 2020). Although they do not exhaust it, the Big Three feature prominently in the hierarchical taxonomy of psychopathology (HiTOP; Kotov et al., 2017). If, as Adler and Clark theorized (2019), narrative-identity factors correlate with HiTOP ones, then a focus on the Big Three is well justified.

To capture traits that underlie the Big Three, we utilized three measures, which vary in the extent to which they frame traits in primarily normal vs. primarily maladaptive terms. First, the Schedule of Nonadaptive and Adaptive Personality (SNAP; Clark, 1993, 1999) is based on a threefactor model and measures basic emotional experience and behaviors to index Positive and Negative Temperament, and Disinhibition. These scales do not tap psychopathology directly.

Second, the NEO Five-factor Inventory (NEO-FFI; Costa \& McCare, 1992) is based on the five-factor model and captures Extraversion, Neuroticism, and Conscientiousness, along with Agreeableness and Openness. Unlike items from the SNAP scales above, some of the NEO-FFl's items reflect a degree of psychopathology (especially within Neuroticism).

Third, we included the Weinberger Adjustment Inventory - Short Form (WAI-SF; 
Weinberger, 1997) for replication purposes and because it measures trait-like psychopathology constructs. Its Distress scale captures Negative Emotionality as internalizing symptoms, and its Self-restraint scale captures (low) Constraint as maladaptive impulsivity and delinquency. To complement the WAI-SF's scales with a clinical-psychological measure of anhedonic detachment (or maladaptively low Positive Emotionality), we adopted the SNAP's Detachment subscale.

This selection of trait measures (see Table 1) enabled us to replicate Blagov and Singer's (2004) method and to pursue additional hypotheses and exploratory analyses linking features of SDMs (and, therefore, narrative identity) to specific personality traits from the Big Three domains.

\section{SDM Features within the Structure of Narrative Identity}

In a major review (Adler et al., 2016), the known variables of narrative identity formed four conceptual domains: affective themes, motivational themes, narrative structure, and integrative meaning. Modeling with a large dataset with 16 variables (McLean et al., 2020) uncovered a similar structure, except that a single factor explained both affective and motivational themes. The SDM features from Blagov and Singer's (2004) study resemble aspects of this new, three-factor model.

1. SDM Affect. The felt positive and negative affect of SDMs are variables subsumed under Motivational and Affective Themes in McLean et al.'s (2020) model. Consistent with the SDM theory, SDMs' affect seems to be linked to their felt importance (Ritchie et al., 2014); to reflect individual differences in self-image, goals or needs; and to convey how much goals or needs are being met (Philippe et al., 2011; Sutin \& Robins, 2008).

SDM affect is likely multiply determined. It may be influenced by individual differences in the extent to which people use the recall of positive AMs to improve their moods (Rusting \& DeHart, 2000). Conversely, mood (Loeffler et al, 2013) and emotion-regulation efforts can modulate affect in AM recall (Wood \& Conway, 2006). A few studies have linked AM or SDM affect to isolated traits (e.g., Denkova et al., 2012). Traits likely influence SDM affect indirectly, by biasing mood and cognitive-affective processes. Internalizing psychopathology (Sanson-Daly et al., 2015) and attachment insecurity (Sutin \& Gillath, 2009) may promote negative affect in SDMs and, perhaps, 
reduce their positive affect. Emotional avoidance may limit the use of positive memories to repair mood (Vanderlind et al., 2017). Thus, positive and negative SDM affect should align with our indices of Positive Emotionality and Negative Emotionality.

The Motivational and Affective Themes factor of narrative identity also includes patterns in emotional-tone transitions in life events. Two broad patterns are redemption (when troubling events end with marked improvement of the self) and contamination (when favorable or ambivalent events end on an irrevocably sour note; McAdams et al., 2001). Such themes have been linked to wellbeing, depression, neuroticism, and distress (Adler et al., 2006). Therefore, we expected contamination to correlate with those of our indices of Negative Emotionality that included psychopathology-laden items (Neuroticism and Distress).

2. SDM Specificity. Blagov and Singer (2004) conceptualized specificity as an aspect of narrative structure, because specific and nonspecific SDMs have different ingredients and timelines. Specific SDMs convey unique experiences (singular actions, emotions, images, dialogue) from brief events (less than a day). Conversely, nonspecific SDMs convey abstractions, semantics, or blended events with longer timelines (more than a day).

Specificity resembles but is not identical to the Facts facet of the Narrative Structure factor from McLean et al.'s (2020) model. This factor concerns the organization and coherence of life-story units (e.g., sufficient detail; clear chronology; internal consistency). For example, narrative structure improves with higher Facts, as this entails "statements of action, description, causal information, emotional behaviors, and quotes" (McLean et al., 2020, p. 927). Specificity, like Facts, is needed to evaluate whether the person's interpretation of events is coherent with their details. Thus, SDM specificity is likely to have similar implications to Facts regarding Narrative Structure, but this is yet to be shown empirically. Therefore, we remain agnostic about its true link to that factor.

SDM specificity (an SDM variable) is more clearly related to the clinical concept of overgeneral AM (a person variable). We suspect that overgeneral AM is an important, though not the only determinant of low specificity. Overgeneral AM (see Williams, 2006) is defined as the 
failure to recall unique, singular events in response to prompts or within a time limit. Instead, the person conveys abstract summaries or semantics about the past. Overgeneral AM results in low specificity, but the latter does not necessarily imply overgeneral AM. Large effect sizes link reduced AM specificity to the presence and risk of depressive, psychotic, and trauma-related disorders and perhaps eating and personality pathology (Ros et al., 2017). Williams (2006), in his capture and rumination, functional avoidance, and executive control (CarFAX) theory, proposed three nonmutually exclusive causes of overgeneral AM. We briefly address each one in turn.

The Emotional Disorder Thesis. Disorders characterized by overgeneral AM involve rumination over painful ideas (Williams, 2006) and perhaps cause reduced SDM specificity. In addition, distress (Barry et al., 2019; Blagov \& Singer, 2004) and dysphoria (Romero et al., 2014) may be linked to reduced recall of specific positive AMs in non-clinical samples. Among the traits we selected, this implicates Neuroticism and Distress (though not necessarily Negative Temperament) in reduced specific and specific positive SDMs.

The Executive Dysfunction Thesis. Because executive processes guide the retrieval of event details (although poignant stimuli may also trigger recall), overgeneral AM may be due to executive dysfunction (Williams, 2006) in clinical and, perhaps, other populations. This implicates our indices of Constraint (Disinhibition, Conscientiousness, and Self-restraint) as predictors of specific SDMs.

The Avoidance Thesis. A third cause of overgeneral AM may be automatic cognitive avoidance due to trauma (Williams, 2006) or avoidant attachment (Edelstein, 2006). Such avoidance is akin to repressive defensiveness. Avoidance (Ros et al., 2017) and defensiveness (Blagov \& Singer, 2004) have been linked to low AM specificity, but not consistently so. Avoidance implicates Detachment from among the Big Three measures and Defensiveness from the 2004 study.

\section{SDM Integration or Meaning Making. The narrative-identity factor Autobiographical}

Reasoning (McLean et al., 2020) captures the degree of reflection (e.g., awareness of insights, lessons, or transitions in life). Subsumed within it is SDM integration, defined as meaning making stated spontaneously and explicitly in the narrative: a lesson learned from the event, a relationship 
affirmation, or the deliberate use of the SDM for self-regulation (Singer \& Blagov, 2004). Below, instead of integration, we will refer to "meaning making," which is the term used most often (albeit with varying operationalizations) in narrative-identity research. Individual differences in meaning making (McLean \& Fournier, 2008) seem moderately stable over time (McLean \& Pasupathi, 2011). It has been linked to the events' perceived impact; less negative and more positive affect about negative events; self-esteem; optimism; and identity development (e.g., Bauer et al., 2005; Liao et al., 2018; Wood \& Conway, 2006). It may be linked to non-defensiveness (Lardi et al., 2012), conscientiousness, emotional stability, and extraversion (e.g., Lodi-Smith et al., 2009).

Overall, well-being and mental health relate to meaning making in AMs (Tavernier \& Willoughby, 2012), in the life story (Adler et al., 2016), and in more general event-related contexts (Park, 2010). Meaning may derive from trauma as well as triumphs, so its links to well-being and mental health are complex. In some studies, it predicts maladjustment, perhaps because of method factors and because the use of meaning can range from constructive, to unhelpful, to self-defeating (Park, 2010). In SDMs, we view it as generally adaptive. It is thought to enable people to revise their identities and goals based on experience and reflection (Singer et al., 2013).

Preliminary evidence suggests that meaning making about negative AMs may protect from distress (Korte et al., 2012; Meisels \& Grysman, 2020) and promote emotion regulation (Cox \& McAdams, 2014). If so, then perhaps SDM meaning making buffers the link between unpleasant events and scores on Distress (our most clinical measure of Negative Emotionality).

4. SDM Content. Narrative content refers to salient motivations or concerns in AMs. SDMs differ in their relational, achievement-oriented, power-oriented, and other potential themes (Blagov \& Singer, 2004). Such themes in SDMs have been linked to personal strivings, expectancies, and cognitive-affective schemas (McLean \& Thorne, 2003; Sutin \& Robins). We focused on the two types of content most common in emerging adults' SDMs: relationships and achievement.

Defined in this way, SDM content appears to be at least conceptually related to the Communion and Agency facets of the Motivational and Affective Themes narrative-identity factor. 
This is based, for example, on the readily apparent overlap between the content coding manual informing our work (see McLean \& Thorne, 2003) and systems for coding intimacy/communion and achievement/agency motivational themes. In narrative-identity theory, such themes are thought to reflect the person's goals or life concerns (Adler et al., 2016), analogous to SDM content. However, the link we draw between SDM content and Motivational and Affective Themes requires explicit empirical testing. It is possible that SDM content (as we defined it) does not map onto McLean et al.'s (2020) model of narrative-identity factors, whose test did not include content variables. In fact, McLean et al. (2016) have suggested that types of content are best thought of as marking different domains of identity development, whereas narrative identity is ultimately about process.

We expect traits to predict trait-congruent content, and Negative Emotionality (especially Distress) to predict frustrated goals or needs (e.g., disrupted relationships and achievement failures). Such traits as extraversion and conscientiousness have been linked to relational and achievement goals and their attainment in AMs (Manczak et al., 2014; Roberts et al., 2004) and to trait-congruent SDM content (Sutin \& Robins, 2005). Achievement and intimacy motives seem to predict well-being (Philippe et al., 2011). Still, the relevant literature is limited and its methods varied. We retested Blagov and Singer's (2004) hypotheses linking Distress to SDM content.

\section{Predictions}

SDM Affect. We predicted that SNAP Positive Temperament would correlate with selfreported positive affect and (negatively) with negative affect in SDMs, and that SNAP Negative Temperament would evidence the inverse pattern of associations with the SDM affect variables. We predicted that NEO-FFI Extraversion would correlate with self-reported positive and (inversely) negative affect, and that the opposite pattern would hold for NEO-FFI Neuroticism. WAI-SF Distress should predict negative affect and (inversely) positive affect in SDMs, and SNAP Detachment should predict low positive SDM affect. Separate from the replication effort, Neuroticism and Distress, but not Negative Temperament, would correlate with themes of contamination.

SDM Specificity. The three sets of predictions we made about specificity are not mutually 
exclusive. First, under the emotional disorder thesis, SDM specificity would correlate negatively with Distress and Neuroticism. We did not expect a link between specificity and Negative Temperament, because psychopathology is not addressed in the item content of the Negative Temperament scale. Second, under the executive functioning thesis, all three indices of Constraint (SNAP Disinhibition, NEO-FFI Conscientiousness, and WAI-SF Self-restraint) should predict reduced SDM specificity in the logical directions. And third, under the avoidance thesis, specificity would correlate negatively with Detachment and (replicating Blagov \& Singer, 2004) WAI-SF Repressive Defensiveness.

To help clarify whether emotional disorder, executive control, or avoidance are linked to SDM specificity in general or only to the specificity of positive SDMs, we tested the same hypotheses with the latter as the criterion. The prediction that specific positive memories would correlate negatively with Distress aimed to replicate Blagov and Singer's (2004) finding.

SDM Meaning Making. Attempting to replicate a key finding by Blagov and Singer (2004), we predicted that Self-restraint would have a curvilinear relationship with SDM meaning making, whereby moderate restraint would be linked to the highest number of memories that contained explicit meaning making. We also had the nonspecific expectation that SDM meaning making would correlate with personality variables in general, in the directions suggestive of adaptive personality.

SDM Content. Like Blagov and Singer (2004), we predicted that Distress would correlate in the logical directions with SDM themes of improved relationships, disrupted relationships, achievement failures, and achievement successes.

Moderation. Based on the proposal that meaning making may buffer distress, we predicted that SDM meaning making would buffer the link between SDM affect and Distress.

Exploratory Analyses (EAs). From the measures outlined above, we planned to derive estimates of the Big Three trait domains: Positive and Negative Emotionality and Constraint, for use in EAs. We planned to report EAs linking all personality dimensions to all SDM variables.

\section{Method}

\section{Participants and Power}


Undergraduate participants $(N=133,77 \%$ women, $73 \%$ White, $M$ age $=19.8, S D=1.36)$, recruited via convenience sampling, received $\$ 30$ or course credit for taking a two-part, secure online survey. (See Appendix SC in the Supplementary Materials for details.) Of 158 volunteers, 133 completed Part 1 , and 120 completed both parts with no missing data. The two parts $(\approx 90$ min. each) were 1-2 weeks apart. The time gap likely minimized testing and state-dependent effects, increasing the likelihood that any findings reflect personality. Part 1 included the 10 SDM Tasks and WAI-SF, and Part 2 - the SNAP, NEO-FFI, and other measures.

Multilevel modeling (MLM) with over 100 participants and 10 SDMs per participant is wellpowered (> .85 for medium effects sizes; Scherbaum \& Ferreter, 2009) and provides accurate estimates at $\alpha=.05$ (Maas \& Hox, 2005). As extreme scores are of interest in the study of adaptive and maladaptive personality, we did not seek or delete outliers.

\section{Self-report Questionnaires}

The Self-defining Memory Task (Appendices SA \& SB) invited participants to write 10 SDMs (word count $M=162, M d=139, S D=96.2$ ) and then rate each one on 12 emotions on a scale from 1 (not at al) to 7 (extremely). For each SDM, we derived Positive and Negative Affect from the means of the respective emotion ratings, as in prior research. We operationalized SDM Affect as the difference between Positive Affect and Negative Affect. Table 2 contains descriptives.

The Schedule for Nonadaptive and Adaptive Personality (SNAP; Clark, 1993) elicits selfreport on 371 items rated as true or false. It yields scores on three temperament dimensions (Negative Temperament, 28 items, Positive Temperament, 27 items, and Disinhibition, 35 items) and 13 subscales, including Detachment (18 items).

The NEO Five-Factor Inventory (NEO-FFI; Costa \& McCrae, 1992), a brief version of the NEO Personality Inventory, yields scores on Extraversion, Neuroticism, Conscientiousness, Agreeableness, and Openness (12 items each). Participants responded on a scale from 1 (strongly disagree) to 5 (strongly agree), instead of the original 7-point one, to ease administration.

The Weinberger Adjustment Inventory - Short Form (WAI-SF; Weinberger et al., 1997) 
measures Distress (anxiety, depression, low self-esteem, and low well-being; 12 items), Selfrestraint (impulse control, suppression of aggression, consideration of others, and responsibility; 12 items), and Defensiveness (denial of normative distress and claims of absolute restraint; 11 items). Participants rated how well items described them (from 1, false, to 5, true) or how often they thought, felt, or acted in certain ways (from 1, almost never, to 5, almost always).

\section{Narrative Coding Manuals}

The Classification System and Scoring Manual for SDMs (Singer \& Blagov, 2000; www.selfdefiningmemories.com) enables trained raters to code SDMs for five levels of specificity and four levels of integrative meaning making. As our research aimed to detect any degree of specific detail, SDMs were coded as specific (1) vs. nonspecific (0). Each SDM was coded as integrative (1) or non-integrative (0). In determining whether a specific SDM was specific positive, we subtracted its Negative Affect from its Positive Affect score.

The Manual for Coding Events in SDMs (Thorne \& McLean, 2001;

www.selfdefiningmemories.com) allows raters to code SDMs for six types of event content, of which we focused on relationship and achievement (as explained above). We subdivided them into improved or worsened relationships (mutually exclusive) and achievement success or failure (also mutually exclusive) based on the same rules that Blagov and Singer (2004) followed.

The Coding Systems for Contamination and Redemption, $3^{\text {rd }}$ and $4^{\text {th }}$ rev. (McAdams, 19981999; https://sites.northwestern.edu/thestudyoflivesresearchgroup) guided decisions whether an SDM had a theme of contamination, redemption, or neither (see the definitions above).

\section{Coding Procedures}

A clinical scientist with expertise in the coding systems was the criterion coder. The principal trained coder, who had a BA in psychology and was not familiar with the hypotheses, coded the SDMs in a randomized order (to reduce within-participant carryover effects on coding). Employing a single coder may minimize unsystematic error due to rater effects but does not protect from rater bias or drift. Therefore, we compared SDM ratings by the principal and criterion raters (100 SDMs at 
Time 1 and 50 SDMs at Times 2 and 3 each) and discussed disagreements (see Table 2 \& Table S9); in such cases, consensus ratings were used. Mean Cohen's $\kappa$ (across Times 1-3) ranged from .66 for improved relationships to .81 for meaning.

\section{Data Reduction}

To estimate the Big Three from the SNAP, NEO-FFI, and WAI-SF, we saved regressionbased factor scores from an extraction of three principal components from the three triads of scales (using IMB SPSS 26) to represent Positive and Negative Emotionality, and Constraint (Table S11).

\section{Replication and Statistical Considerations}

Whereas Blagov and Singer's (2004) survey was on paper, ours was online. In other respects, Part 1 of the procedure was identical to theirs. Measures not collected in 2004 were administered in Part 2. We recruited a demographically similar sample with statistically equivalent gender-identity composition and mean levels of integrative SDMs, Distress, and Self-restraint (Table S12). Our sample had slightly higher age and levels of specific, success, and failure SDMs. The same coding manuals were employed (except for the purposes of extension).

A key difference was in our statistical approach. Blagov and Singer (2004) treated SDM variables as individual differences and averaged each one across 10 SDMs per participant (like item scores on a unifactorial measure). Lardi et al. (2012) argued for predicting variables at the SDM level using multilevel modeling (MLM) to account for nesting of SDMs within persons. We adopted their approach. (In practice, inferences from MLM and bivariate analyses were often equivalent.) One advantage of MLM is that it may boost effective sample size and, thus, power. The exception to using MLM was testing the moderation hypothesis, where the outcome variable was Distress at the person level (not for separate SDMs) and ordinary multiple regression was appropriate (FosterJohnson \& Kromrey, 2018). In other respects, our statistical approach conformed to Blagov and Singer's. For example, we adopted $\alpha=.05$ (two-tailed tests to offset multiplicity). We did not covary out demographics, given our replication goal, the sample's relatively homogeneity, and potential covariates' generally negligible correlations with key variables (e.g., sex, age; Table S4). 


\section{Results}

Table 3 contains the results from MLM tests predicting SDM features from personality traits, including hypothesis tests and exploratory analyses (EAs). Visualizations of key results appear in Figures 1, S2, and S3. EAs linking SDM features to the Big Three's estimates appear in Table S10. Tests from the Replication Attempt

SDM Affect. In a replication of Blagov and Singer's (2004) findings, Distress correlated with Negative Affect and (inversely) Positive Affect, as hypothesized.

SDM Specificity. As was our prediction, we replicated the negative link between Distress and specific positive SDMs. We did not find support for the hypothesis that Distress would predict fewer specific SDMs, consistent with Blagov and Singer's (2004) nonsignificant result. We failed to replicate their finding of a negative link between Defensiveness and specific SDMs.

SDM Meaning Making. The replication hypothesis that Self-restraint would have a quadratic relationship to meaning-making SDMs did not receive support - we detected a rectilinear relationship instead. This overlaps with Blagov and Singer's (2004) results only partially, in that low Self-restraint corresponded to lack of meaning making.

SDM Content. We found support for the replication hypotheses that Distress would predict worsened relationships and Self-restraint would predict achievement successes in SDMs. Like Blagov and Singer (2004), we did not find support for the hypotheses that Distress would correlate with more achievement failures and fewer improved relationships in SDMs.

\section{Tests of New Hypotheses and EAs}

\section{SDM Affect}

Positive Temperament, Extraversion, and Detachment correlated with SDM Positive Affect, in the hypothesized directions. We did not detect Positive Temperament's and Extraversion's predicted links to Negative Affect. (In an EA, Extraversion predicted less contamination.)

Negative Temperament, Neuroticism, and Distress evidenced the hypothesized links to Negative Affect, Positive Affect, and contamination, in the expected directions. (We already 
commented on links between Distress and SDM affect under Tests from the Replication Effort.)

In summary, all measures of Positive Emotionality predicted Positive Affect, but only the one with psychopathology content (Detachment) predicted Negative Affect in SDMs. All measures of Negative Emotionality predicted contamination as well as Negative and (inversely) Positive Affect in SDMs. Respectively, in EAs, Positive Emotionality predicted Positive Affect, whereas Negative Emotionality was linked to contamination and both high Negative and low Positive Affect in SDMs.

\section{SDM Specificity}

Like Distress (see above), Neuroticism correlated negatively with specific positive SDMs, consistent with our hypothesis. Also, similar to Distress, and contrary to our prediction, we did not detect a negative link between Neuroticism and specific SDMs.

As hypothesized, (low) Disinhibition, Conscientiousness, and Self-restraint predicted specific SDMs. Contrary to expectations, we detected no links of (low) Disinhibition and Conscientiousness with specific SDMs. However, Self-restraint did predict specific SDMs, as expected.

The hypothesis that Defensiveness would predict specific positive SDMs found no support. (This parallels the finding regarding specific SDMs; see above.) Opposite to predictions, Detachment correlated positively with specific SDMs; in an EA, so did Extraversion, negatively. Detachment did not evidence the expected negative link to specific positive SDMs.

In summary, Negative Emotionality measures that include pathology-laden items predicted fewer specific positive SDMs but not specific SDMs. All Constraint indices predicted specific SDMs. Respectively, in EAs, Positive Emotionality was linked to specific as well as specific positive SDMs; Negative Emotionality - to fewer specific positive SDMs; and Constraint - to fewer specific SDMs.

\section{SDM Meaning Making}

As noted earlier, Self-restraint had a rectilinear (not the expected quadratic) link to meaningmaking SDMs. We had made no other specific predictions about links between traits and meaning making. In EAs, meaning-making SDMs were linked to Positive Emotionality traits (Positive Temperament, Extraversion, inversely - Detachment), Negative Emotionality traits (Neuroticism and 
Distress, inversely), and Constraint traits (Self-restraint, as already noted, and, inversely Disinhibition), and Agreeableness. In further EAs, meaning-making SDMs were correlated with the Positive Emotionality, Negative Emotionality (inversely), and Constraint factors. The overall pattern suggests a broadband linkage between meaning-making SDMs and adaptive personality.

\section{SDM Content}

Above, we commented on Distress's relationships to SDM content variables. In EAs, like Distress, Neuroticism predicted less achievement success, as did the broader Negative Emotionality factor. In further EAs, Positive Temperament correlated with SDM improved relationships and achievement success. Similarly, Extraversion was linked to achievement success, and Detachment had negative associations with improved relationships and achievement success. Respectively, Positive Emotionality predicted improved relationships and achievement success. Conscientiousness and Self-restraint correlated negatively with achievement failure, as did the broader Constraint factor.

In summary, Positive Emotionality measures predicted satisfying content in SDMs, measures of Constraint predicted lack of disappointments in achievement, and the pattern was less clear for Negative Emotionality.

\section{Test of the Moderation Hypothesis}

Together, SDM Affect $\left(b=-0.23, p=2.8^{-5}\right.$, bootstrapped bias-corrected $95 \%$ C.I. $=[-0.33-$ $0.13])$ and meaning-making SDMs $(b=-0.13, p=.103$, b.c. $95 \%$ C.I. $=[-0.08-0.01])$ explained a significant amount of variation in Distress $\left(R^{2}=.162, p=1.0^{-5}\right)$. As predicted, adding the Affect $\mathrm{x}$ Meaning-making SDMs interaction term improved the model $\left(\Delta R^{2}=.033, p=.023\right)$, yielding a significant interaction $(b=0.05, p=.023$, b.c. $95 \%$ C.I. $=[0.01-0.10])$. As shown in Figure 1 , the link between SDM Affect and Distress was strong when meaning-making SDMs were absent, and it steadily declined with increasing numbers of meaning-making SDMs. Thus, meaning-making SDMs moderated (or buffered) the link between Affect and Distress (see also Figure S1).

In summary, 21 hypotheses received support, whereas 13 did not. 


\section{Discussion}

We conducted a replication and extension of Blagov and Singer's (2004) work. In doing so, we interrelated a set of narrative features of SDMs to personality dispositions representing the Big Three. The SDM features resemble elements from the new structural model of narrative identity (McLean et al., 2020). The Big Three - Positive Emotionality, Negative Emotionality, and Constraint - are influential in trait models of personality and psychopathology (Watson et al., 2006). Although our inferences are limited by a U.S. undergraduate sample of modest size and heterogeneity, this study is a preliminary step toward meeting three important goals.

One goal was conceptual. It was to discuss how SDMs, as units of analysis in the life story, and the SDM features we studied, fit within the emerging empirical model of narrative-identity factors (McLean et al., 2020). Such discussion is needed as narrative-identity researchers arrive at consensus definitions and the field comes of age.

We view SDMs as differing from other AMs not in kind but in the extent of their importance and centrality among the events that comprise narrative identity. In our project, SDM affect, redemption, and contamination are constructs subsumed within the higher-order factor of Motivational and Affective Themes of narrative identity. SDM specificity resembles (but is not identical to) the Facts facet of the factor Narrative Structure. SDM meaning making, as a form of explicit, narrative meaning making, falls under Autobiographical Reasoning. SDM content is not represented in the narrative-identity model, (despite limited resemblance to facets of Motivational and Affective Themes), perhaps because content is not seen as a narrative process (McLean et al., 2016). Below, we comment on our project's two empirical goals, those of replication and extension.

\section{Conclusions from the Replication Effort}

As noted above, one of our goals was a close replication of the frequently cited 2004 study by Singer and Blagov on links between narrative features of AMs and adaptive personality. Despite major advances (Adler et al., 2016), the field of narrative-identity research suffers from a lack of replication attempts, and we sought to partially remedy this. 
We replicated the relationships between Distress (a clinically formulated measure of Negative Emotionality) and the SDM variables Negative Affect, (low) Positive Affect, (low) specific positive SDMs, worsened relationships, and (low) achievement success. Like Blagov and Singer (2004), we found no links of Distress with specific SDMs, or achievement failures, or (low) improved relationships. We could replicate neither the link between Defensiveness and specific SDMs, nor the well-cited 2004 finding of a quadratic relationship between Self-restraint and meaning-making SDMs (whereby unrestrained persons yielded the least and moderately restrained ones yielded the most meaning making). However, we found a positive link between them. We have, then, replicated the pattern that unrestrained participants are least likely to volunteer explicit meaning in SDMs. Finally, we did not replicate the link between Defensiveness and specific SDMs.

Thus, five tests replicated successfully (statistically significant in both studies), three were nonsignificant in both studies, two failed to replicate (significant only in the older study), and one was borderline. The inconclusive hypothesis tests and failed replications may be due to several reasons. Such reasons may include limited validity of theories; the older study's reliance on singlelevel models (which limit power by ignoring SDMs' nesting within persons); differences between samples (recruited years and over a thousand miles apart); and, of course, measurement error.

Our confidence is greatly increased in those results that replicated, at least in young U.S. undergraduates with our sample's characteristics. In this population, Negative Emotionality (when clinically formulated) is linked to narrative-identity variables from McLean et al.'s (2020) Motivational and Affective Themes factor, to narrative content, and to reduced specificity for positive events (which may be linked to the Narrative Structure factor). Furthermore, Constraint is linked to a meaning-making variable from the Autobiographical Reasoning narrative-identity factor.

These findings bridge basic dimensions of personality and psychopathology (Watson et al., 2006) with narrative identity (Adler et al., 2016; McAdams, 2018; McLean et al., 2020). Our remaining goal was, albeit in a methodologically modest manner, to extend this effort.

\section{Conclusions from the Extension Effort}


Our findings bear on the pursuit (recommended by Adler et al., 2019) of understanding how the structures of (a) narrative identity and (b) adaptive and maladaptive personality relate. Just as the SDMs we studied index the emerging model of narrative identity, so the Big Three trait factors Positive Emotionality, Negative Emotionality, and Constraint - are pivotal in the structure of traits and psychopathology (Markon et al., 2005; Wright et al., 2012; Kotov et al., 2017). We extend the literature by linking SDM features to three sets of trait measures that index the Big Three but differ in the extent to which they capture normal vs. maladaptive personality. This helps to situate indices of narrative-identity factors (SDM features) against the Big Three (trait measures). Below, we discuss the results grouped by SDM features.

1. SDM Affect. Hypotheses receiving support included that Positive Temperament, Extraversion, and (low) Detachment would predict SDM Positive Affect, and that Negative Temperament, Neuroticism, and Distress would predict SDM Negative Affect and contamination themes in SDMs. Unsupported were the hypotheses that Positive Temperament and Extraversion would predict SDM Negative Affect.

This means that, in terms of the Big Three, all Negative Emotionality but not the Positive Emotionality traits were linked to felt negative emotion and contamination in SDMs. In contrast, Negative Emotionality traits (inversely) and Positive Emotionality traits correlated with felt positive emotion in SDMs. The inconclusive results about a relationship between Positive Emotionality and negative emotion in SDMs parallel prior research on traits and retrieval bias (Mayo, 1983) or everyday emotions (Komulainen et al., 2014). It corresponds to psychopathology's broader links to Negative and narrower links to Positive Emotionality.

Overall, such results link facets of Motivational and Affective Themes in narrative identity (affective features of SDMs) to the Positive Emotionality and Negative Emotionality trait domains. A parsimonious explanation for these associations is that emotional predispositions (Positive and Negative Emotionality) cause individual differences in narrative thought. These associations may, however, be multiply determined and causally reciprocal. For example, SDM affect may depend on 
mood (Loeffner et al., 2013), self-regulation (Richards \& Gross, 2006), psychopathology, and goal attainment. Furthermore, SDM Negative Affect's links to Negative Temperament, Neuroticism, and Distress may be at least in part due to differential factors (e.g., low self-regulation skills for Neuroticism and obstructed or unrealistic goals for Distress; Lecci et al., 1994). In at least one study (Philippe et al., 2011), need satisfaction predicted AM affect incrementally over traits. Research should address further how and why narrative-identity factors and traits are linked.

2. SDM Specificity. Hypotheses receiving support included that specific SDMs would correlate with Disinhibition (inversely), Conscientiousness, and Self-restraint, and that positive specific SDMs would predict Neuroticism (inversely), Distress (inversely), and Self-restraint. We did not find support for the hypotheses that specific SDMs would correlate negatively with Detachment, Neuroticism, and Distress, or that specific positive SDMs would be linked negatively to Disinhibition, Detachment, and Defensiveness, or positively to Conscientiousness. Overall, specificity was linked to Constraint and, for emotionally positive narratives, to those conceptualizations of Negative Emotionality that included pathology-related item content (Neuroticism and Distress).

The findings regarding SDM specificity may have implications for the CarFAX theory of overgeneral AM (Williams, 2006), at least in a non-clinical, undergraduate sample. It is notable that Constraint correlated with specific SDMs. As self-report measures of Constraint and executive dysfunction likely tap both constructs (Buchanan, 2016), the results tentatively support the executive dysfunction thesis of overgeneral AM. Research should address whether this is due to reduced ability or merely low effort in retrieving or sharing event-specific details.

Regarding the emotional disorder thesis from the CarFAX theory, Negative Emotionality indices did not show the expected negative correlations with specific SDMs. However, two such indices (Neuroticism and Distress) were linked inversely to specific positive SDMs. This parallels prior findings linking Negative Emotionality indices to reduced specific positive AMs (Barry et al., 2019; Blagov \& Singer, 2004; Romero et al., 2014). Furthermore, one index of Constraint - Selfrestraint - correlated with specific positive SDMs. The commonality among Neuroticism, Distress, 
and Self-restraint is that they have psychopathology-related item content. Thus, reduced specificity in positive SDMs may require an explanation other than the explanation for reduced specificity regardless of emotion. The results support the emotional disorder thesis, with the qualification that only specific positive recall, not all specific recall, may be implicated in the population we studied. Perhaps overgenerality (Williams, 2006) as an impairment extends more broadly to AM in clinical samples, where executive dysfunction and emotional disorder are more likely to coincide. However, overgenerality may be restricted to positive specific AMs in undergraduates, who probably would be unable to remain in college if emotional disorder and executive dysfunction were both present.

This leads to the possibility that Negative Emotionality and Constraint may interact in predicting Narrative Structure. Such an interaction may account for the markedly low narrative coherence in the AMs of persons with borderline personality features (Adler et al., 2012) - features that reflect extreme negative emotionality and low constraint, along with severe identity problems.

Contrary to the avoidance thesis (Edelstein, 2006; Williams, 2006), Detachment correlated positively with specific SDMs and evidenced no link to specific positive SDMs; Defensiveness evidenced no associations with either. This further detracts from the thesis that overgeneral AMs are due to avoidance (Ros et al., 2017), but it may reflect limitations of the measures. Detachment may not differentiate among interpersonal, attachment, and experiential avoidance, while capturing anhedonic and schizoid features. Defensiveness may reflect adaptive personality, as noted below.

3. SDM Meaning Making. As noted earlier, we could not replicate a quadratic relationship between Self-restraint and meaning-making SDMs. In exploratory analyses, higher levels of meaning-making SDMs corresponded to the more adaptive poles of the traits: Positive Temperament, Extraversion, (low) Detachment, (low) Neuroticism, (low) Distress, Agreeableness, (low) Disinhibition, Self-restraint, as well as Defensiveness (which likely reflects positive self-image and self-presentation in this context). We found support for the hypothesis that meaning-making SDMs would buffer the link between SDM Affect and trait Distress. Below, we briefly discuss first the general pattern of relationships, and then the buffering (moderation or interaction) effect. 
The findings suggest that Positive Emotionality, Negative Emotionality (inversely), and Constraint all predict this facet of the narrative-identity factor Autobiographical Reasoning. It is possible that adaptive traits promote this kind of explicit, spontaneous meaning making. It is also possible that the Big Three's maladaptive poles, too, were linked to meaning making, but it was negative, and participants did not disclose it. Also plausible is the theory that meaning making in SDMs promotes adaptive personality functioning in non-clinical populations (Singer et al., 2013). It may do so by allowing experience and reflection to guide the construal of the self in the life-story and the flexible selection of worthwhile goals. Preliminary evidence (Liao et al., 2018) suggests that meaning making in SDMs may mediate the link between SDM valence (an aspect of experience) and self-esteem (an aspect of the self). Future research may tease apart alternative explanations for adaptive traits' links to the meaning-making facet of the Autobiographical Reasoning factor.

The moderation (Figure 1) demonstrates that aspects of Autobiographical Reasoning (i.e., meaning-making SDMs) and Motivational and Affective Themes (i.e., SDM Affect) may interact in predicting aspects of well-being (trait Distress). In this college sample, the tendency to recall negative memories was a stronger predictor of Distress among participants who wrote down the fewest meaning-making SDMs and a weaker to nonsignificant one among the rest. Albeit crosssectional, this finding supports the thesis that meaning making is adaptive (Park, 2010; Singer et al., 2013). Presumably, even when needs are unmet and negative SDM recall predominates, meaning making can weaken the SDM affect-distress link by enabling the person to reflect and adapt. Perhaps this is why meaning making is seen as a key mechanism of change in psychotherapy (Castonguay \& Beutler, 2006). It may also help to account for the health benefits from disclosing emotional, personal material (Frattaroli, 2006). Future research may show whether the finding replicates and entails causal mechanisms, and which ones.

4. SDM Content. As noted earlier, we replicated the 2004 findings that Distress correlates with SDMs about worsened relationships and (inversely) achievement success. However, also consistent with the 2004 results, we did not find the expected associations between Distress and 
achievement failures or (low) improved relationships. In exploratory analyses, Positive Temperament and (inversely) Detachment predicted improved relationships; Positive Temperament, Extraversion, Detachment (inversely), and Neuroticism (inversely) predicted achievement success; and Conscientiousness and Self-restraint predicted fewer achievement failures in SDMs. The findings are in line with research linking SDM content to personal motives (Sutin \& Robins, 2008)

SDM content variables likely reflect motivational processes, and their mean levels and relationship to traits may be especially sample-dependent. In this college sample, all indices of Positive Emotionality and two indices of Constraint correlated with themes of achievement success and failure. Only indices of Positive Emotionality correlated with improved relationships. Perhaps we sampled from a population in which salient achievement motivation readily reflects the Big Three. That motivational tendencies captured via the Big Three related to SDM content is consistent with the notion that mental health partly derives from goal attainment vs. frustration (Lecci et al., 1994). Limitations and Strengths

Key limitations of this research include the cross-sectional, correlational design; a modest convenience sample of mostly undergraduate women of limited diversity; imperfect (yet substantial) inter-rater reliability; and the reliance on a single primary coder (as opposed to using consensus or averaging across coders; see Adler at al., 2017). The study's strengths included the replication component; 10 SDMs per participant; well-powered MLM; and that the significant results linking self-reported to researcher-coded data cannot be due to shared method variance. Our analyses did not correct for attenuation, thus likely underestimating the strength and number of associations. The sample's homogeneity may have caused underestimation of some effects (by restricting the ranges of some variables). It likely limits the findings' generalizability, but it may have favored power by limiting error variance due to cultural, age, or cohort effects.

For replication purposes, we coded narrative variables dichotomously. This may not be optimal, especially if the latent narrative constructs are dimensional. Although the taxonicity vs. dimensionality of such variables has not been tested, researchers (e.g., Adler et al., 2006; Cox \& 
McAdams, 2014; Wood \& Conway, 2006) have sometimes measured them dimensionally.

Unlike prior studies (see Alder et al., 2016), themes of redemption outnumbered

contamination ones and did not predict relevant constructs. This may be due to differences in sampling participants, eliciting narratives, units of analysis, or coding practices across studies. The component parts of contamination sequences are thought to be more closely linked in rememberers' minds than those in redemption sequences (McAdams et al., 2001). Thus, written SDMs absent querying by researchers may be less likely to yield an entire redemption sequence than an entire contamination sequence, especially as compared to narratives obtained orally through the Life Story Interview with follow-up querying by the interviewer (Adler et al., 2017).

The findings, of course, do not signify causal effects. The links between narrative-identity variables and adaptive personality traits may reflect shared causes; traits may influence both narrative identity and psychological health; psychological disorders may alter personality and autobiographical narratives; personality and psychopathology may bias SDM recall; and SDMs may inform self-concept and mood-regulation, thus biasing the self-report of traits.

\section{Conclusion}

Self-defining memories (SDM) are useful units of analysis of narrative identity, whose features resemble elements from the emerging model of broad narrative-identity factors (McLean et al., 2020). We demonstrated that, albeit labor-intensive (Adler et al., 2017), narrative research lends itself to replication. We also showed that SDM features relate meaningfully to the Big Three of personality and psychopathology. Such research on a larger scale may clarify how narrative-identity and trait-domain structures relate (see Adler et al., 2019). We found further support for Williams's (2006) executive dysfunction and emotional disorder theses of overgeneral AM. We also showed that spontaneous, explicit meaning making in narrative identity may serve as a buffer between the recall of unpleasant memories and chronic distress. The findings hint at SDMs' potential in applied research, for example, as sources of information in evaluating people's ongoing concerns and, perhaps, targets of intervention regarding distress (Çili \& Stopa, 2014; Singer et al., 2013). 


\section{References}

Adler, J.M., Chin, E.D., Kolisetty, A.P., \& Oltmanns, T.F. (2012). The distinguishing characteristics of narrative identity in adults with features of borderline personality disorder: An empirical investigation. Journal of Personality Disorders, 26(4), 498-512.

Adler, J.M. \& Clark, L.A. (2019). Incorporating narrative identity into structural approaches to personality and psychopathology. Journal of Research in Personality, 82, 103857.

Adler, J. M., Dunlop, W. L., Fivush, R., Lilgendahl, J. P., Lodi-Smith, J., McAdams, D. P., ... Syed, M. (2017). Research methods for studying narrative identity: A primer. Social Psychological and Personality Science, 8(5), 519-527.

Adler, J.M., Lodi-Smith, J., Philippe, F.L., \& Houle, I. (2016). The incremental validity of narrative identity in predicting well-being: A review of the field and recommendations for the future. Personality and Social Psychology Review, 20(2), 142-175.

Adler, J.M., Kissel, E.C., \& McAdams, D.P. (2006). Emerging from the CAVE: Attributional style and the narrative study of identity in middle adulthood. Cognitive Therapy and Research, $30(1), 39-51$.

Barry, T.K., Vinograd, M., Boddez, Y., Raes, F., Zinbarg, R., Mineka, S., \& Craske, M.G. (2019). Reduced autobiographical memory specificity affects general distress through poor social support. Memory, 27(7), 916-923.

Bauer, J.J., McAdams, D.P., \& Sakaeda, A.R. (2005). Interpreting the good life: Growth memories in the lives of mature, happy people. Journal of Personality and Social Psychology, 88(1), 203-217.

Blagov, P.S., \& Singer, J.A. (2004). Four empirically derived dimensions of self-defining autobiographical memories (structure, meaning, content, and affect) and their relationships to social-emotional maturity, distress, and repressive defensiveness. Journal of Personality, $72,481-511$.

Buchanan, T. (2016). Self-report measures of executive function problems correlate with 
personality, not performance-based executive function measures, in non-clinical samples. Psychological Assessment, 28(4), 372-385.

Çili, S., \& Stopa, L. (2014). The retrieval of self-defining memories is associated with the activation of specific working selves. Memory, 23(2), 233-253.

Castonguay, L., \& Beutler, L. (2006). Principles of therapeutic change that work. Oxford.

Clark, L.A. (1993). Schedule for Nonadaptive and Adaptive Personality. University of Minnesota.

Clark, L.A. (1999). Temperament: A new paradigm for trait psychology. In L.A. Pervin and O.P. John (Eds.), Handbook of personality: Theory and research, $2^{\text {nd }}$ ed, pp. 399-423. Guilford.

Conway, M. A., Singer, J. A., \& Tagini, A. (2004). The self and autobiographical memory: Correspondence and coherence. Social Cognition, 22, 495-537.

Costa, P.T., \& McCrae, R.R. (1992). NEO PI-R. Professional manual. Psychological Assessment.

Cox, K., \& McAdams, D.P. (2014). Meaning making during high and low point life story episodes predicts emotion regulation two years later. Journal of Research in Personality, 50, 66-70.

Denkova, E., Dolcos, S., \& Dolcos, F. (2012). Reliving emotional personal memories: Affective biases linked to personality and sex-related differences. Emotion, 12(3), 515-528.

Edelstein, R.S. (2006). Attachment and emotional memory: Investigating the source and extent of avoidant memory impairments. Emotion, 6, 340-345.

Fivush, R. (2014). The development of autobiographical memory. Annual Review of Psychology, 62, $559-82$.

Foster-Johnson, L., \& Kromrey, K.D. (2018). Predicting group-level outcome variables: An empirical comparison. Behavioral Research Methods, 50, 2461-2479.

Frattaroli, J. (2006). Experiential disclosure and its moderators: A meta-analysis. Psychological Bulletin, 132(6), 823-865.

Habermas, T., \& Bluck, S. (2000). Getting a life: The emergence of the life story in adolescence. Psychological Bulletin, 126, 748-769.

Komulainen, E., Meskanen, K., Lipsanen, J., Lahti, J.M., Jylhä, P., Melartin, T., ... Ekelund, J. 
(2014). The effect of personality on daily life emotional processes. PLOS One, e110907.

Korte, J., Cappeliez, P., Bohlmeijer, E.T., \& Westerhof, G.J. (2012). Meaning in life and mastery mediate the relationship of negative reminiscence with psychological distress among older adults with depressive symptoms. European Journal of Ageing, 9(4), 343-351.

Kotov, R., Krueger, R. F., Watson, D., Achenbach, T. M., Althoff, R. R., ... Zimmerman, M. (2017). The hierarchical taxonomy of psychopathology (HiTOP): A dimensional alternative to traditional nosologies. Journal of Abnormal Psychology, 126(4), 454-477.

Lardi, C., Ghisletta, P., \& Van der Linden, M. (2012). What is the nature of the self-defining memories of repression-prone individuals? Self and ldentity, 11, 492-515.

Lecci, L., Okun, M.A., \& Karoly, P. (1994). Life regrets and current goals as predictors of psychological adjustment. Journal of Personality and Social Psychology, 66(4), 731-741.

Liao, H.W., Bluck, S., \& Westerhof, G.J. (2018). Longitudinal relations between self-defining memories and self-esteem: Mediating roles of meaning-making and memory function. Imagination, Cognition, and Personality, 37(3), 318-341.

Lodi-Smith, J., Geise, A.C., Roberts, B.W., \& Robins, R.W. (2009). Narrating personality change. Journal of Personality and Social Psychology, 96(3), 679-689.

Loeffler, S.N., Myrtec, M., \& Peper, M. (2013). Mood-congruent memory in daily life: Evidence from interactive ambulatory monitoring. Biological Psychology, 93, 308-315.

Luchetti, M., Rossi, N., \& Montebarocci, O. (2016). Collecting self-defining memories outside therapy. Clinical Psychologist, 20, 80-85.

Maas, C.J.M., \& Hox, J.J. (2005). Sufficient sample sizes for multilevel modeling. Methodology, 1(3), 86-92.

Manczak, E.M., Zapata-Gietl, C., \& McAdams, D.P. (2014). Regulatory focus in the life story: Prevention and promotion as expressed in three layers of personality. Journal of Personality and Social Psychology, 106(1), 169-181.

Markon, K.E., Krueger, R.F., \& Watson, D. (2005). Delineating the structure of normal and abnormal personality: An integrative hierarchical approach. Journal of Personality and Social 
Psychology, 88, 139-157.

Mayo, P.R. (1983). Personality traits and the retrieval of positive and negative memories. Personality and Individual Differences, 4(5), 465-471.

McAdams, D.P. (2018). Narrative identity: What is it? What does it do? How do you measure it? Imagination, Cognition, and Personality, 37(3), 359-372.

McAdams, D.P., Reynolds, J., Lewis, M., Patten, A., \& Bowman, P. (2001). When bad things turn good and good things turn bad. Personality and Social Psychology Bulletin, 27(4), 474-485.

McLean, K.C., \& Fournier, M.A. (2008). The content and process of autobiographical reasoning in narrative identity. Journal of Research in Personality, 42, 527-545.

McLean, K.C., \& Pasupathi, M. (2011). Old, new, borrowed, blue? The emergence and retention of personal meaning in autobiographical storytelling. Journal of Personality, 79(1), 135-163.

McLean, K.C., Syed, M., Pasupathi, M., Adler, J. M., Dunlop, W. L., Drustrup, D., ... McCoy, T. P. (2020). The empirical structure of narrative identity: The initial Big Three. Journal of Personality and Social Psychology, 119(4), 920-944.

McLean, K.C., Syed, M., \& Shucard, H. (2016). Bringing identity content to the fore: Links to identity development processes. Emerging Adulthood, 4(5), 356-363.

McLean, K.C., \& Thorne, A. (2003). Late adolescents' self-defining memories about relationships. Developmental Psychology, 39(4), 635-645.

Meisels, H.B., \& Grysman, A. (2020). Confronting self-discrepant events: Meaning making and wellbeing in personal and political narratives. Self \& Identity, 20(3), 323-338.

Park, C. (2010). Making sense of the meaning making literature: An integrative review of meaning making and its effects on adjustment to stressful life events. Psychological Bulletin, 136(2), 257-301.

Philippe, F.L., Koestner, R., Beaulieu-Pelletier, G., \& Lecours, S. (2011). The role of needs satisfaction as a distinct and basic psychological component of autobiographical memories: A look at well-being. Journal of Personality, 79(5), 905-938. 
Ritchie, T.D., Skowronski, J.J., Cadogan, S., \& Sedikides, C. (2014). Affective responses to selfdefining autobiographical events. Self and Identity, 13(5), 513-534.

Roberts, B.W., O'Donnell, M., \& Robins, R.W. (2004). Goal and personality trait development in emerging adulthood. Journal of Personality and Social Psychology, 87(4), 541-550.

Romero, N., Vazquez, C., \& Sanchez, A. (2014). Rumination and specificity in autobiographical memory in dysphoria. Memory, 22(6), 646-654.

Ros, L., Latorre, J.M., Serrano, J.P., \& Ricarte, J.J. (2017). Overgeneral autobiographical memory in healthy young and older adults: Differential age effects on components of the CaRFAX model. Psychology and Aging, 32(5), 447-459.

Rusting, C.L., \& DeHart, T. (2000). Retrieving positive memories to regulate negative mood: Consequences for mood-congruent memory. Journal of Personality and Social Psychology, 78(4), 737-752.

Sanson-Daly, U. M., Bryant, R. A., Cohn, R. J., \& Wakefield, C. E. (2015). Rumination and selfdefining memories in the context of health concerns. Memory, 24, 1-10.

Scherbaum, C.A., \& Ferreter, J.M. (2009). Estimating statistical power and required sample sizes for organization research using multilevel modeling. Organizational Research Methods, 12(2), 347-367.

Sellbom, M., Carragher, N., Sunderland, M., Calear, A.L., \& Batterham, P.J. (2020). The role of maladaptive personality domains across multiple levels of the HiTOP structure. Personality and Mental Health, 14, 30-50.

Singer, J. A. (1990). Affective responses to autobiographical memories and their relationship to long-term goals. Journal of Personality, 58, 535-563.

Singer, J.A., \& Blagov, P.S. (2004). The integrative function of narrative processing:

Autobiographical memory, self-defining memories and the life story of identity. In D.R. Beike, J.M. Lampinen, \& D.A. Behrend (Eds.), The self and memory. Psychology Press. Singer, J.A., Blagov, P., Berry, M., \& Oost, K.M. (2013). Self-defining memories, scripts, and the 
life story: Narrative identity in personality and psychotherapy. Journal of Personality, 81(6), 569-582.

Sutin, A.R., \& Gillath, O. (2009). Autobiographical memory phenomenology and content mediate attachment style and psychological distress. Journal of Counseling Psychology, 56, 351-364.

Sutin, A.R., \& Robins, W. (2005). Continuity and correlates of emotions and motives in self-defining memories. Journal of Personality, 73(3), 793-824.

Sutin, A.R., \& Robins, R.W. (2008). Going forward by drawing from the past: Personal strivings, personally meaningful memories, and personality traits. Journal of Personality, 76, 631-663.

Tavernier, R., \& Willoughby, T. (2012). Adolescent turning points: The association between meaning making and psychological well-being. Developmental Psychology, 42, 1058-1068.

Vanderlind, W.M., Stanton, C.H., Weinbrecht, A., Velkoff, E.A., \& Joormann, J. (2017). Remembering the good ole days: Fear of positive emotion relates to affect repair using positive memories. Cognitive Therapy and Research, 41(3), 362-368.

Watson, D., Kotov, R. \& Gamez, W. (2006). Basic dimensions of temperament in relation to personality and psychopathology. In R.F. Krueger and J.L. Tackett (Eds.), Personality and psychopathology, pp. 7-38. Guilford.

Weinberger, D.A. (1997). Distress and self-restraint as measures of adjustment across the life span: Confirmatory factor analyses in clinical and nonclinical samples. Psychological Assessment, $9(2), 132-135$

Williams, J. (2006). Capture and rumination, functional avoidance, and executive control (CaRFAX): Three processes that underline overgeneral memory. Cognition and Emotion, 20, 248-568.

Wood, W.-J., \& Conway, M. (2006). Subjective impact, meaning making, and current and recalled emotions for self-defining memories. Journal of Personality, 74(3), 811-845.

Wright, A.G.C., Thomas, K.M., Hopwood, C.J., Markon, K.E., Pincus, A.L., \& Krueger, R.F. (2012). The hierarchical structure of DSM-5 personality pathology traits. Journal of Abnormal Psychology, 121(4), 951-957. 
Table 1

Measures of the Big Three Trait Domains and Their Face-valid Psychopathology Item Content

Face-valid Psychopathology Content

Big Three Trait Domains Free of pathology-laden items Contain psychopathology items

Positive Emotionality $\quad$ SNAP Positive Temperament $\quad$ SNAP Detachment (inverse)

NEO-FFI Extraversion

Negative Emotionality $\quad$ SNAP Negative Temperament $\quad$ NEO-FFI Neuroticism

WAI-SF Distress

Constraint SNAP Disinhibition (inverse) WAI-SF Self-restraint

NEO-FFI Conscientiousness

\begin{tabular}{lll}
\hline Other personality $\quad$ WAI-SF Defensiveness & NEO-FFI Agreeableness
\end{tabular}

trait dimensions NEO-FFI Openness

Note: SNAP - Schedule of Nonadaptive and Adaptive Personality; NEO-FFI - NEO Five-factor Inventory; WAI-SF - Weinberger Adjustment Inventory - Short Form. 


\section{Table 2}

Descriptive Statistics and Reliability Estimates

\begin{tabular}{|c|c|c|c|c|c|c|c|c|}
\hline Study Variables & & Des & script & tive $\mathrm{S}$ & Statis & tics & & Reliability \\
\hline Personality and Adjustment & $N$ & Scale & $M$ & Md & $S D$ & Min. & Max. & $\alpha$ (Items) \\
\hline NEO-FFI Openness & 120 & $1-5$ & 3.8 & 3.8 & 0.55 & 2.5 & 4.8 & $.79(12)$ \\
\hline NEO-FFI Agreeableness & 120 & $1-5$ & 3.8 & 3.8 & 0.56 & 2.3 & 5.0 & $.83(12)$ \\
\hline NEO-FFI Extraversion & 120 & $1-5$ & 3.5 & 3.5 & 0.61 & 2.0 & 4.9 & $.83(12)$ \\
\hline NEO-FFI Neuroticism & 120 & $1-5$ & 3.0 & 3.0 & 0.71 & 1.4 & 4.5 & $.87(12)$ \\
\hline NEO-FFI Conscientiousness & 120 & $1-5$ & 3.7 & 3.8 & 0.58 & 2.1 & 5.0 & $.83(12)$ \\
\hline SNAP Positive Temperament & 120 & $0-1$ & .69 & .70 & .19 & .22 & 1 & $.85(27)$ \\
\hline SNAP Negative Temperament & 120 & $0-1$ & .50 & .48 & .25 & .04 & .93 & $.89(28)$ \\
\hline SNAP Disinhibition & 120 & $0-1$ & .29 & .26 & .14 & .06 & .83 & $.66(35)$ \\
\hline SNAP Detachment & 120 & $0-1$ & .34 & .33 & .24 & 0 & .94 & $.81(18)$ \\
\hline WAI-SF Distress & 133 & $1-5$ & 2.7 & 2.7 & 0.71 & 1.4 & 5.0 & $.88(12)$ \\
\hline WAI-SF Self-restraint & 133 & $1-5$ & 4.1 & 4.3 & 0.54 & 1.8 & 5.0 & $.80(12)$ \\
\hline WAI-SF Repressive Defensiveness & 133 & $1-5$ & 2.6 & 2.6 & 0.60 & 1.2 & 4.5 & $.73(11)$ \\
\hline Self-defining Memories (SDMs) & $N$ & Scale & $M$ & Md & $S D$ & Min. & Max. & $\mathrm{K}(\mathrm{SDMs})^{* *}$ \\
\hline Specific $^{*}$ & 133 & $0-10$ & 8.5 & 9.0 & 1.62 & 2 & 10 & $.75-.83(50-100)$ \\
\hline Specific Positive* & 133 & $0-10$ & 5.3 & 5.0 & 2.03 & 1 & 9 & $\mathrm{n} / \mathrm{a}$ \\
\hline Integrative* & 133 & $0-10$ & 2.9 & 2.0 & 2.55 & 0 & 9 & $.79-.86(50-100)$ \\
\hline Relationship Content: Improved* & 133 & $0-10$ & 1.5 & 1.0 & 1.35 & 0 & 6 & $.58-.72(50-100)$ \\
\hline Relationship Content: Worsened* & 133 & $0-10$ & 1.1 & 1.0 & 1.06 & 0 & 4 & $.69-.77(50-100)$ \\
\hline Achievement Success Content* & 133 & $0-10$ & 3.0 & 3.0 & 2.05 & 0 & 9 & $.77-.83(50-100)$ \\
\hline Achievement Failure Content ${ }^{*}$ & 133 & $0-10$ & 1.1 & 1.0 & 1.08 & 0 & 4 & $.69-.73(50-100)$ \\
\hline Redemption Theme* & 133 & $0-10$ & 0.7 & 0 & 0.95 & 0 & 4 & $.66-.73(50-100)$ \\
\hline Contamination Theme* & 133 & $0-10$ & 1.8 & 1.0 & 1.64 & 0 & 7 & $.67-.80(50-100)$ \\
\hline Affect Ratings: Positive factor & 133 & $1-7$ & 3.3 & 3.4 & 0.85 & 1.1 & 5.6 & $\alpha=.83(10)$ \\
\hline Affect Ratings: Negative factor & 133 & $1-7$ & 2.1 & 2.0 & 0.69 & 1.0 & 4.2 & $\alpha=.93(10)$ \\
\hline
\end{tabular}

${ }^{*}$ Descriptives based on totals (all others based on means across subscale items). NEO-FFI: NEO

Five-Factor Inventory. SNAP: Schedule of Nonadaptive and Adaptive Personality. WAI-SF:

Weinberger Adjustment Inventory - Short Form.

** 100 SDMs at Time 1 and 50 SDMs at Times 2 and 3 each. 
Table 3

Multilevel Modeling Results Linking Narrative Features of Self-defining Memories to Personality Dimensions. (Attempts at replication (AR)

and exploratory (E) analyses are marked with abbreviations.)

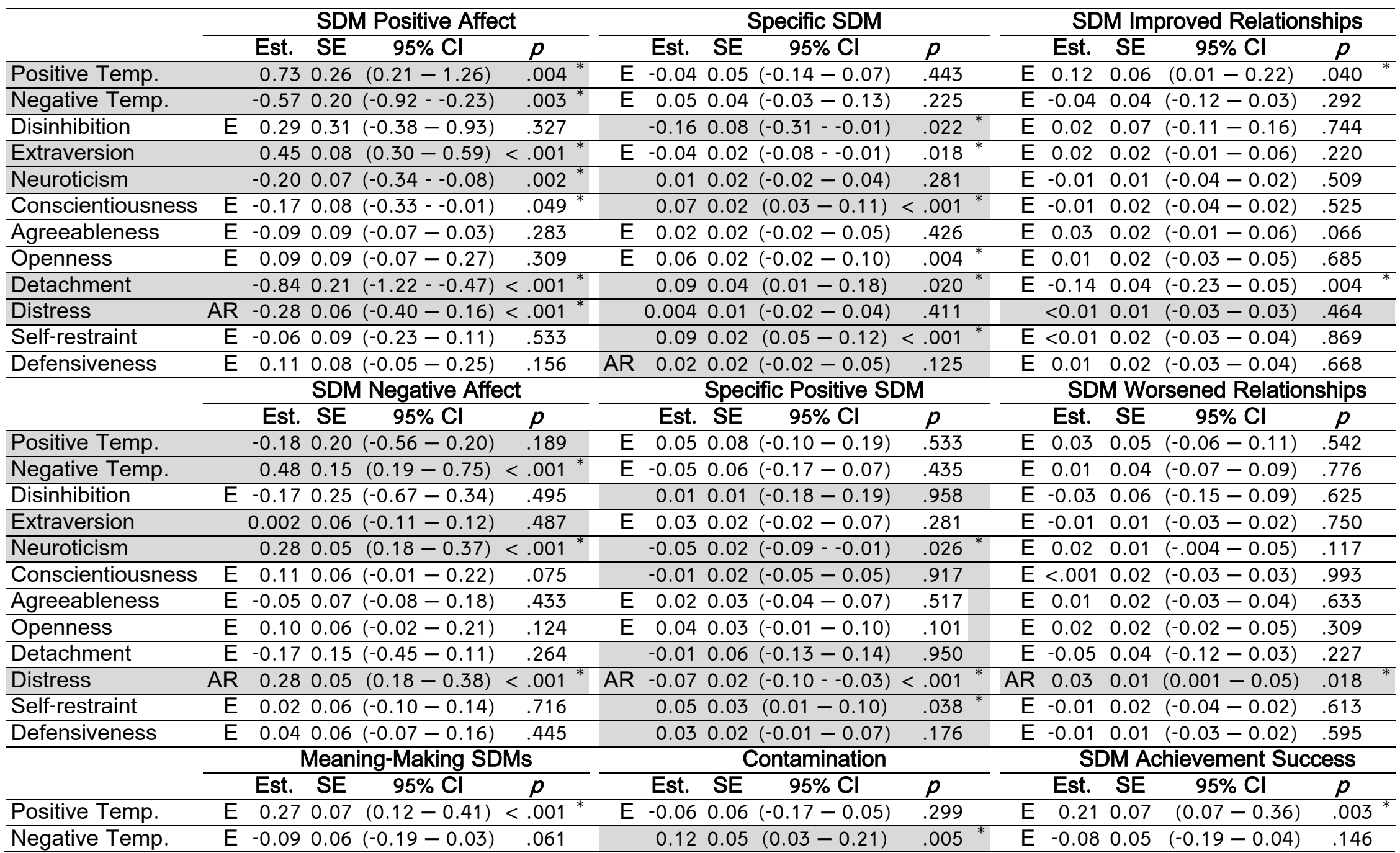




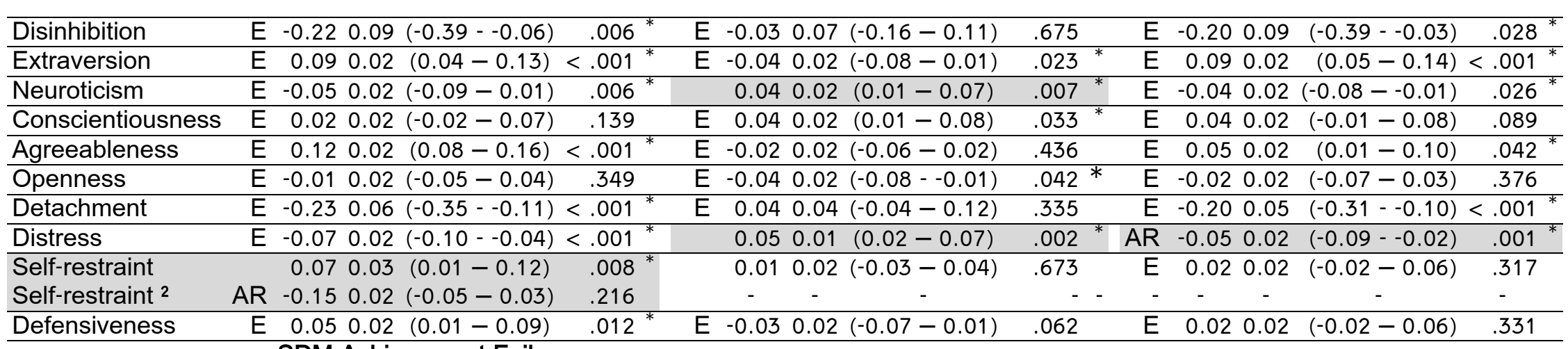

\section{SDM Achievement Failure}

\section{Est. SE $95 \% \mathrm{Cl}$}

\begin{tabular}{lcrrrr}
\hline Positive Temp. & E & 0.03 & 0.05 & $(-0.06-0.13)$ & .505 \\
\hline Negative Temp. & E & -0.02 & 0.04 & $(-0.10-0.05)$ & .561 \\
\hline Disinhibition & E & 0.08 & 0.07 & $(-0.06-0.21)$ & .234 \\
\hline Extraversion & E & -0.01 & 0.01 & $(-0.04-0.02)$ & .740 \\
\hline Neuroticism & E & 0.02 & 0.01 & $(-0.01-0.04)$ & .225 \\
\hline Conscientiousness & E & -0.03 & 0.02 & $(-0.06-0.01)$ & $.027^{*}$ \\
\hline Agreeableness & E & -0.01 & 0.02 & $(-0.04-0.02)$ & .418 \\
\hline Openness & E & -0.01 & 0.02 & $(-0.04-0.02)$ & .536 \\
\hline Detachment & E & $<.01$ & 0.04 & $(-0.07-0.07)$ & .982 \\
\hline Distress & & 0.02 & 0.01 & $(-0.01-0.04)$ & .051 \\
\hline Self-restraint & E & -0.04 & 0.02 & $(-0.07-0.01)$ & $.034^{*}$ \\
\hline Defensiveness & E & -0.02 & 0.01 & $(-0.05-0.01)$ & .149
\end{tabular}

Note: REML estimation with $95 \%$ bias-corrected and accelerated Cl bootstrapping with 1000 iterations. All null-model tests were significant at $p<.001$. Tests of a priori hypotheses are shaded. AR: Attempt at replication. E: Exploratory analysis. ${ }^{*} p<.05$ (two-tailed). 10 SDMs per 120-133 participants. 


\section{Figure 1}

The Tendency to Recall Meaning-making SDMs Moderates the Relationship Between Memory Affect and WAI-SF Distress Scores $(N=133)$

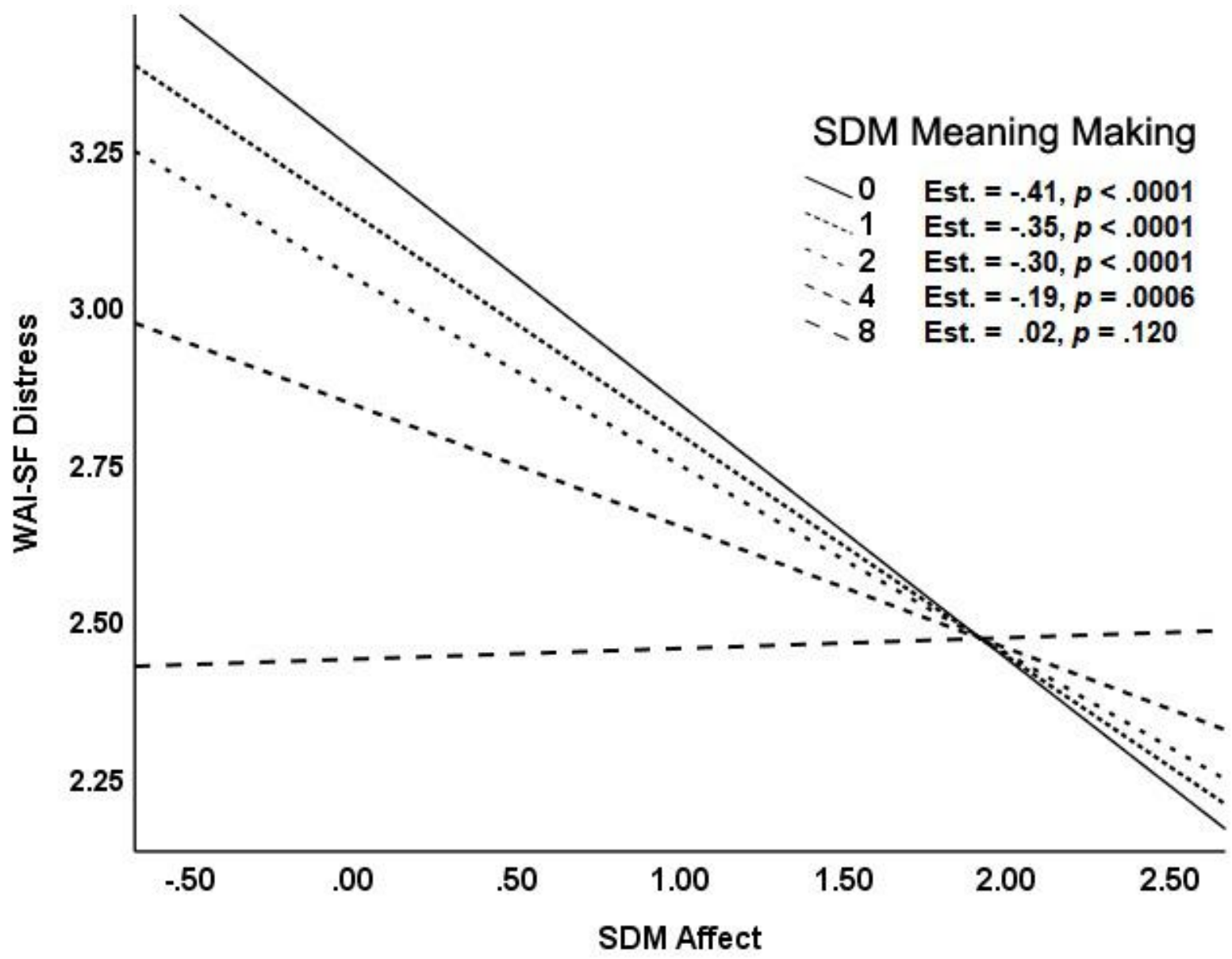

Notes: Probing the interaction at the $5^{\text {th }}, 25^{\text {th }}, 50^{\text {th }}, 75^{\text {th }}$, and $95^{\text {th }}$ percentiles of the moderator. SDMs: Self-defining Memories; WAI-SF: Weinberger Adjustment Inventory - Short Form. 


\title{
Supplementary Materials
}

for

\section{Self-defining Memories - Narrative Features in Relation to Adaptive and Maladaptive}

Personality Traits (Replication and Extension of Blagov \& Singer, 2004)

\author{
Pavel S. Blagov, $\mathrm{PhD}^{1}$ \\ Whitman College \\ Jefferson A. Singer, $\mathrm{PhD}$ \\ Connecticut College \\ Kathryn M. Oost, PhD \\ Bellingham Psychology, Bellingham, WA \\ Joshua A. Goodman, PhD \\ Rhodes College
}

2021

\section{Author notes:}

Correspondence: blagovp@whitman.edu; 345 Boyer Ave., Walla Walla, WA 99362

Data: http://dx.doi.org/10.17632/jv68zhz58s.2

Funding: The authors received no financial support.

Disclosure: The authors declare no potential conflicts of interest.

Ethics: This research complies with federal and institutional ethics guidelines. 


\section{Table of Contents}

Appendix SA: Self-Defining Memory Task ........................................................................

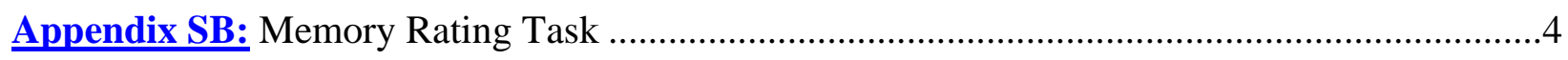

Appendix SC: Expanded Participant Descriptives …......................................................5

Table S1: Descriptive Statistics and Reliability Estimates........................................................6

Table S2: Bivariate Correlations among Personality Variables..............................................7

Table S3: Bivariate Correlations among Self-Defining Memory Variables...............................8

Table S4: Correlations among Study Variables and Potential Covariates.................................9

Table S5: Predicting Self-defining Memory Variables from WAI-SF Distress Subscales ..........10

Table S6: Pearson Correlations between SDM and SNAP Variables ....................................11

Table S7: Pearson Correlations between SDM and NEO-FFI Variables .................................12

Table S8: Pearson Correlations between SDM and WAI-SF Variables ..................................13

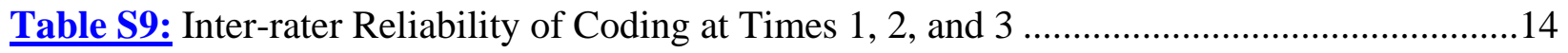

Table S10: Multilevel Modeling Linking SDM Features to the Big Three Superfactors......15

Table S11: Principal Components Analysis of Personality Dimensions (Data Reduction)...16

Table S12: Comparison between the Old (2004) and Current Samples..................................17

Figure S1: An Alternative Visualization of the Interaction between SDM Affect and the

Number of Meaning-making SDMs Recalled in predicting WAI-SF Distress............18

Figure S2: A Visualization of the Hypotheses and Findings Linking Narrative Features of

SDMs and Personality Dimensions ...................................................................................19

Figure S3: Outcomes from the Replication Attempt: A Side-by-Side Presentation of Corresponding Findings from the Original (Blagov \& Singer, 2004) and Current

Studies 


\section{Appendix SA}

\section{The Self-Defining Memory Task}

This part of the study concerns the recall of a special kind of personal memory called a "selfdefining memory." A self-defining memory has the following attributes:

1. It is at least one year old.

2. It is a memory from your life that you remembered very clearly and that still feels important to you even as you think about it.

3. It is a memory about an important enduring theme, issue, or conflict from your life. It is a memory that helps explain who you are as an individual and might be the memory that you would tell someone else if you wanted that person to understand you in a profound way.

4. It is a memory linked to other similar memories that share the same theme or concern.

5. It may be a memory that is positive or negative, or both, in how it makes you feel. The only important aspect is that it leads to strong feelings.

6. It is a memory that you have thought about many times. It should be familiar to you like a picture you have studied or a song (happy or sad) you have learned by heart.

On the next few pages, we ask you to recall and write down several self-defining memories. Please write the memories down as if you were telling them to someone you wanted to get to know you. 


\section{Appendix SB}

\section{Memory Rating Task}

Using the rating scale provided, please indicate how you felt today in recalling and thinking about your memory.
Not
Moder-
Extreme-
at all
ately
ly

$\begin{array}{llllllll}\text { Happy } & 0 & 0 & 0 & 0 & 0 & 0 & 0 \\ \text { Sad } & 0 & 0 & 0 & 0 & 0 & 0 & 0 \\ \text { Angry } & 0 & 0 & 0 & 0 & 0 & 0 & 0 \\ \text { Fearful } & 0 & 0 & 0 & 0 & 0 & 0 & 0 \\ \text { Surprised } & 0 & 0 & 0 & 0 & 0 & 0 & 0 \\ \text { Ashamed } & 0 & 0 & 0 & 0 & 0 & 0 & 0 \\ \text { Disgusted } & 0 & 0 & 0 & 0 & 0 & 0 & 0 \\ \text { Guilty } & 0 & 0 & 0 & 0 & 0 & 0 & 0 \\ \text { Interested } & 0 & 0 & 0 & 0 & 0 & 0 & 0 \\ \text { Embarrassed } & 0 & 0 & 0 & 0 & 0 & 0 & 0 \\ \text { Contemptful } & 0 & 0 & 0 & 0 & 0 & 0 & 0 \\ \text { Proud } & 0 & 0 & 0 & 0 & 0 & 0 & 0\end{array}$

Using the same scale, please rate how important the memory is to you and how vividly you recalled the memory.
Not
Moder-
Extreme-
at all
ately
ly

$\begin{array}{llllllll}\text { Important } & 0 & 0 & 0 & 0 & 0 & 0 & 0 \\ \text { Vivid } & 0 & 0 & 0 & 0 & 0 & 0 & 0\end{array}$

How many years ago did the memory take place?

Years Ago _ _ (to the nearest whole number) 


\section{Appendix SC}

\section{Expanded Participant Descriptives}

The participants $(N=133,77 \%$ women, $23 \%$ men) were $18-24$ years old $(M=19.8, S D=$ $1.36)$, and identified primarily as White (73\%) or Asian/Pacific-islander (16\%; $11 \%$ - Other). They were undergraduates at a private college in the Northwestern U.S. either taking introductory psychology courses or volunteering for a cash payment for "a study on personal memories."

The students had varying seniority (24\% first-years, $29 \%$ sophomores, $22 \%$ juniors, and $25 \%$ seniors), and they reported, on average, excellent high school $(N=129, M=3.8, S D=0.25)$ and college $(N=121, M=3.45, S D=0.35)$ grade-point averages. Similarly, self-reported Scholastic Aptitude Test (SAT) scores were high on the Verbal $(N=113, M=688, S D=76)$ and Mathematics $(N=113, M=661, S D=90)$ subtests.

The majority (85.5\%) identified as heterosexual (14.5\% were lesbian, gay, or bisexual), and their relationship status was typically single (69\%), with $31 \%$ reporting being in a relationship or dating, and none being married.

The most frequent answer to an open-ended question about religious affiliation was "none" (39\%), followed by a Christian denomination (31\%), "atheist" (8\%), "agnostic" (5\%), "Jewish" $(5 \%)$, and other answers $(12 \%)$.

The distribution of self-reported socioeconomic status (SES; $N=131$ ) was as follows: lower or working class, $8 \%$; lower middle class, $9 \%$; middle class, 34\%; upper-middle class, $39 \%$; upper or high class, $9 \%$. The students reported the education level of their mothers or first parents $(N=$ $130)$ and fathers or second parents $(N=129)$. The distribution of education level for mothers or first parents was as follows: lower than a high-school diploma, 2\%; high-school diploma, 8\%; some college, $6 \%$; bachelor's degree, $35 \%$; some post-graduate education, $3 \%$; master's or similar degree, $35 \%$; and doctoral degree, $9 \%$. The respective distribution for fathers or second parents was: lower than a high-school diploma, 3\%; high-school diploma, 7\%; some college or trade school, $8 \%$; bachelor's degree, $31 \%$; some post-graduate education, $2 \%$; master's or similar degree, $28 \%$; and doctoral degree, $19 \%$. 


\section{Table S1}

Descriptive Statistics and Reliability Estimates

\begin{tabular}{|c|c|c|c|c|c|c|c|c|}
\hline Study Variables & & De & scrif & ptive & Stati & stics & & Reliability \\
\hline Personality and Adjustment & $N$ & Scale & $M$ & Md & $S D$ & Min. & Max. & $\alpha($ Items $)$ \\
\hline NEO-FFI Openness & 120 & $1-5$ & 3.8 & 3.8 & 0.55 & 2.5 & 4.8 & $.79(12)$ \\
\hline NEO-FFI Agreeableness & 120 & $1-5$ & 3.8 & 3.8 & 0.56 & 2.3 & 5.0 & $.83(12)$ \\
\hline NEO-FFI Extraversion & 120 & $1-5$ & 3.5 & 3.5 & 0.61 & 2.0 & 4.9 & $.83(12)$ \\
\hline NEO-FFI Neuroticism & 120 & $1-5$ & 3.0 & 3.0 & 0.71 & 1.4 & 4.5 & $.87(12)$ \\
\hline NEO-FFI Conscientiousness & 120 & $1-5$ & 3.7 & 3.8 & 0.58 & 2.1 & 5.0 & $.83(12)$ \\
\hline SNAP Positive Temperament & 120 & $0-1$ & .69 & .70 & .19 & .22 & 1 & $.85(27)$ \\
\hline SNAP Negative Temperament & 120 & $0-1$ & .50 & .48 & .25 & .04 & .93 & $.89(28)$ \\
\hline SNAP Disinhibition & 120 & $0-1$ & .29 & .26 & .14 & .06 & .83 & .66 \\
\hline SNAP Detachment & 120 & $0-1$ & .34 & .33 & .24 & 0 & .94 & .81 \\
\hline WAI-SF Distress & 133 & $1-5$ & 2.7 & 2.7 & 0.71 & 1.4 & 5.0 & $.88(12)$ \\
\hline WAI-SF Self-restraint & 133 & $1-5$ & 4.1 & 4.3 & 0.54 & 1.8 & 5.0 & $.80(12)$ \\
\hline WAI-SF Repressive Defensiveness & 133 & $1-5$ & 2.6 & 2.6 & 0.60 & 1.2 & 4.5 & $.73(11)$ \\
\hline Self-defining Memories (SDMs) & $N$ & Scale & $M$ & Md & $S D$ & Min. & Max. & K (SDMs) ${ }^{* * *}$ \\
\hline Specific* & 133 & $0-10$ & 8.5 & 9.0 & 1.62 & 2 & 10 & $.75-.83(50-100)$ \\
\hline Specific Positive* & 133 & $0-10$ & 5.3 & 5.0 & 2.03 & 1 & 9 & $\mathrm{n} / \mathrm{a}$ \\
\hline Meaning making* & 133 & $0-10$ & 2.9 & 2.0 & 2.55 & 0 & 9 & $.79-.86(50-100)$ \\
\hline Relationship Content: Improved* & 133 & $0-10$ & 1.5 & 1.0 & 1.35 & 0 & 6 & $.58-.72(50-100)$ \\
\hline Relationship Content: Worsened* & 133 & $0-10$ & 1.1 & 1.0 & 1.06 & 0 & 4 & $.69-.77(50-100)$ \\
\hline Achievement Success Content ${ }^{*}$ & 133 & $0-10$ & 3.0 & 3.0 & 2.05 & 0 & 9 & $.77-.83(50-100)$ \\
\hline Achievement Failure Content ${ }^{*}$ & 133 & $0-10$ & 1.1 & 1.0 & 1.08 & 0 & 4 & $.69-.73(50-100)$ \\
\hline Redemption Theme* & 133 & $0-10$ & 0.7 & 0 & 0.95 & 0 & 4 & $.66-.73(50-100)$ \\
\hline Contamination Theme* & 133 & $0-10$ & 1.8 & 1.0 & 1.64 & 0 & 7 & $.67-.80(50-100)$ \\
\hline Affect Ratings: Positive factor & 133 & $1-7$ & 3.3 & 3.4 & 0.85 & 1.1 & 5.6 & $\alpha=.83(10)$ \\
\hline Affect Ratings: Negative factor & 133 & $1-7$ & 2.1 & 2.0 & 0.69 & 1.0 & 4.2 & $\alpha=.93(10)$ \\
\hline
\end{tabular}

*Descriptives based on totals (all others based on means across subscale items). NEO-FFI: NEO Five-Factor Inventory. SNAP: Schedule of Nonadaptive and Adaptive Personality. WAI-SF:

Weinberger Adjustment Inventory - Short Form.

** 100 SDMs at Time 1 and 50 SDMs at Times 2 and 3 each.

Note: This table appears in the manuscript as well as in the Supplementary Materials. 
Table S2

Bivariate Correlations Among Personality Variables, Two-tailed ( $\mathrm{N}=120-133$ )

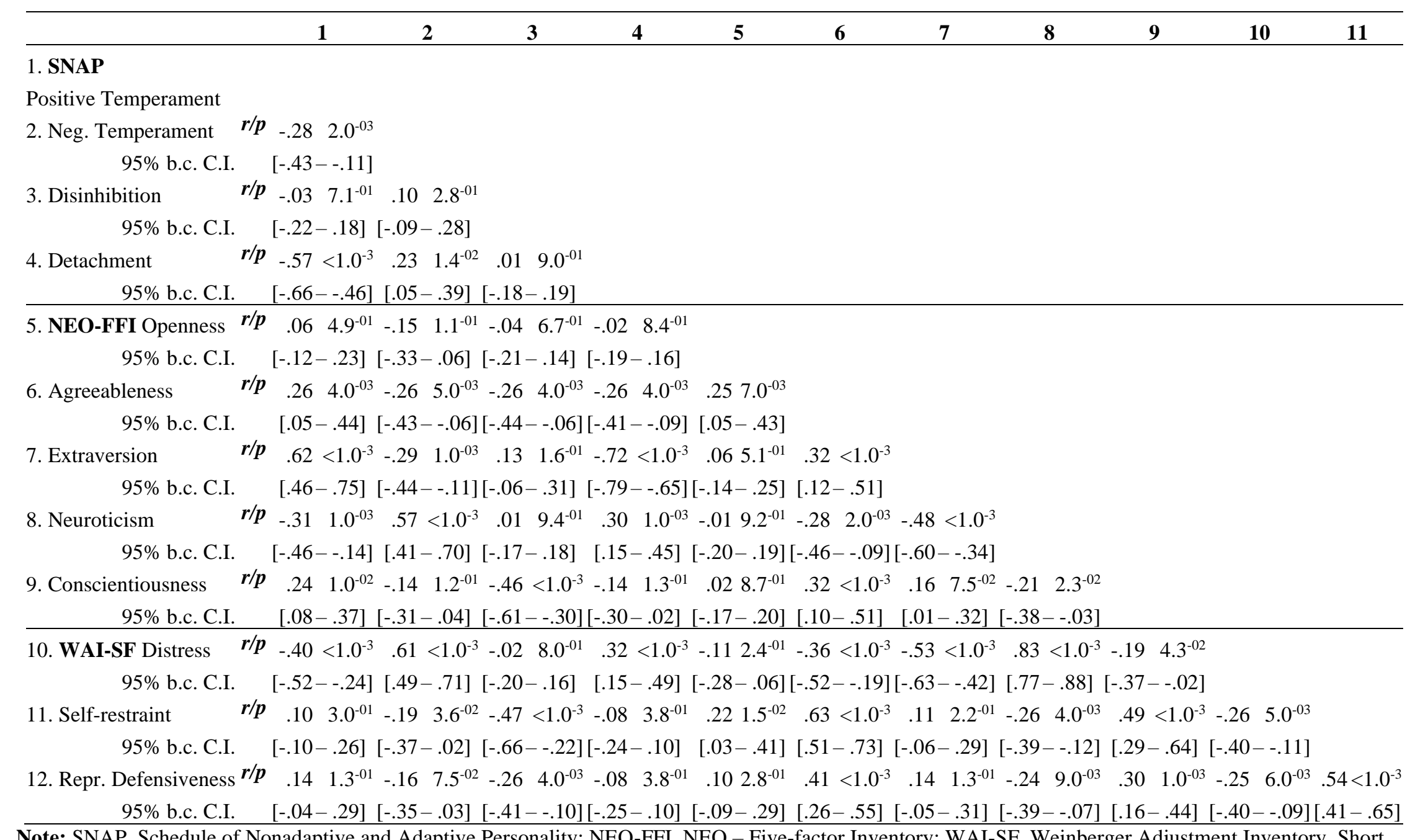

Note: SNAP, Schedule of Nonadaptive and Adaptive Personality; NEO-FFI, NEO - Five-factor Inventory; WAI-SF, Weinberger Adjustment Inventory, Short Form; 95\% bias-corrected confidence-interval bootstrapping estimation based on 1000 iterations. (For small-to-medium bivariate correlations (in EAs in the Supplementary Materials), NHT power at $N=120-133$ was $.72-.76$ for $r=.20$ and $.96-.98$ for $r=.30$.) 


\section{Table S3}

Bivariate Correlations Among Self-Defining Memory Variables, Two-tailed ( $\mathrm{N}=133)$

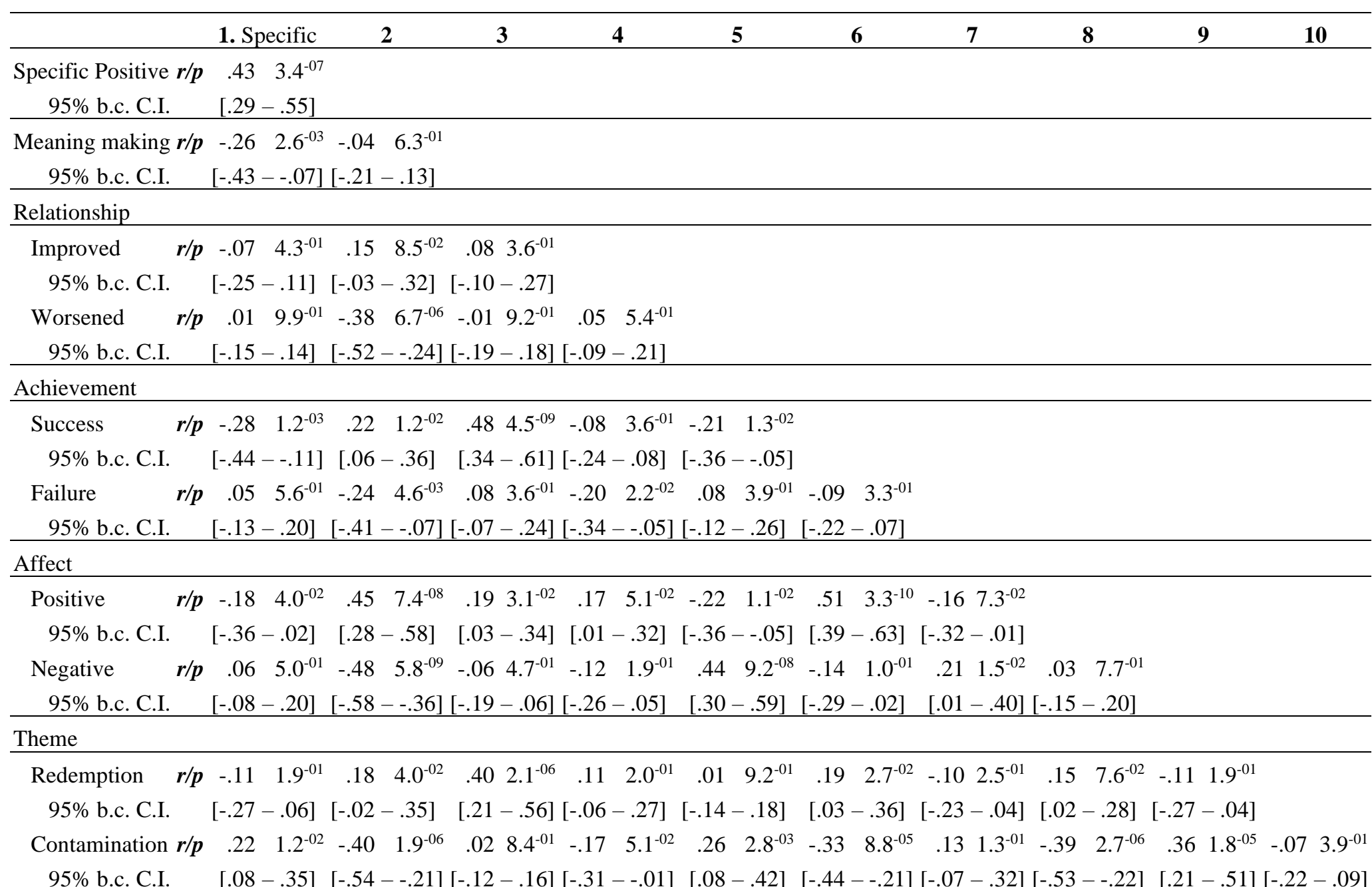

Note: Bias-corrected confidence-interval bootstrapping estimation based on 1000 iterations. (For small-to-medium bivariate correlations (in EAs in the Supplementary Materials), NHT power at $N=120-133$ was $.72-.76$ for $r=.20$ and $.96-.98$ for $r=.30$.) 


\section{Table S4}

Correlations among Study Variables and Potential Covariates, Two-tailed ( $\mathrm{N}=120-133)$

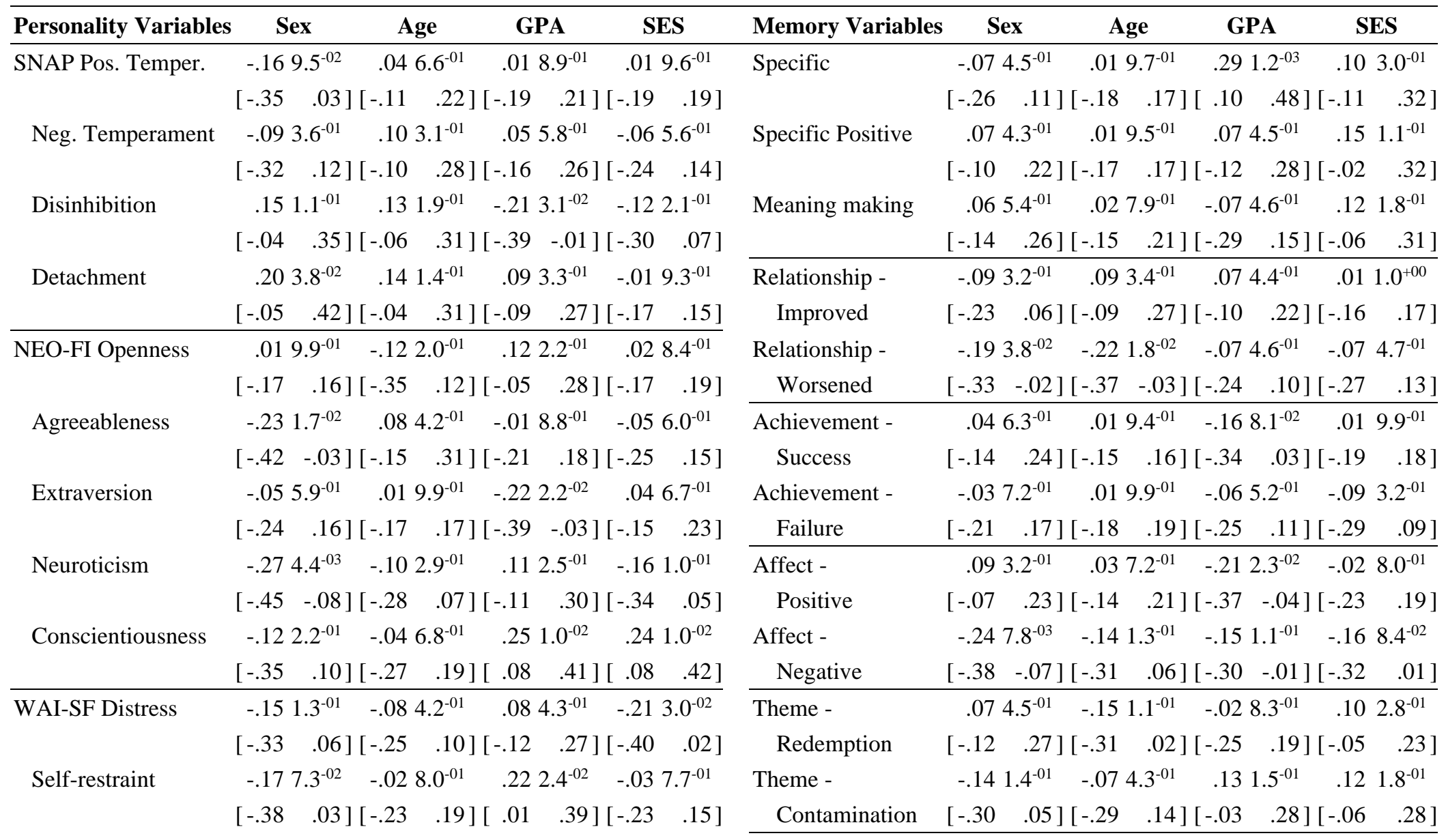

Repressive

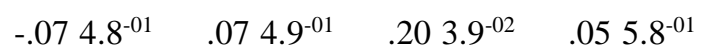

Defensiveness $\quad[-.24 \quad .10]\left[\begin{array}{ll}-.10 & .23\end{array}\right]\left[\begin{array}{ll}.01 & .39\end{array}\right]\left[\begin{array}{ll}-.13 & .22\end{array}\right]$

Note: SNAP, Schedule of Nonadaptive and Adaptive Personality; NEO-FFI, NEO - Five-factor Inventory; WAI-SF, Weinberger Adjustment Inventory - Short Form; Sex, 1 = female, 2 = male; GPA, self-reported college grade point average; SES, socioeconomic status. (For small-to-medium bivariate correlations (in EAs in the Supplementary Materials), NHT power at $N=120-133$ was $.72-.76$ for $r=.20$ and $.96-.98$ for $r=.30$.) 


\section{Table S5}

Exploratory Analyses: Predicting Self-defining Memory Variables from WAI-SF Distress Subscale Scores $(\mathrm{N}=133)$.

\begin{tabular}{|c|c|c|c|c|c|c|c|c|c|c|c|c|c|c|}
\hline $\begin{array}{l}\text { Self-defining memory } \\
\text { variables }\end{array}$ & & sitive & $\mathrm{Me}$ & kning- & $\begin{array}{r}\text { Relat } \\
\text { imp }\end{array}$ & $\begin{array}{l}\text { ionship, } \\
\text { roved }\end{array}$ & Achie & evement & & $\begin{array}{l}\text { sitive } \\
\text { ffect }\end{array}$ & $\mathrm{Ne}$ & $\begin{array}{l}\text { gative } \\
\text { ffect }\end{array}$ & & $\begin{array}{l}\text { ntam- } \\
\text { ation }\end{array}$ \\
\hline WAI-SF Distress & $R^{2}$ & Adj. $R^{2}$ & $R^{2}$ & $\operatorname{Adj.} R^{2}$ & $R^{2}$ & $\operatorname{Adj.} R^{2}$ & $R^{2}$ & $\operatorname{Adj.} R^{2}$ & $R^{2}$ & Adj. $R^{2}$ & $R^{2}$ & $\operatorname{Adj.} R^{2}$ & $R^{2}$ & $\operatorname{Adj.} R^{2}$ \\
\hline subscales & .08 & .06 & .08 & .05 & .05 & .02 & .08 & .05 & .11 & .08 & .10 & .08 & .06 & .03 \\
\hline & $\beta$ & $p$ & $\beta$ & $p$ & $\beta$ & $p$ & $\beta$ & $p$ & $\beta$ & $p$ & $\beta$ & $p$ & $\beta$ & $p$ \\
\hline Anxiety & -.13 & .217 & .11 & .286 & .08 & .424 & .14 & .173 & -.08 & .412 & .13 & .223 & .18 & .093 \\
\hline Depression & .11 & .381 & .01 & .985 & .21 & .099 & -.01 & .983 & .22 & .078 & .11 & .373 & -.01 & .920 \\
\hline Low Self-esteem & -.27 & .042 & -.23 & .083 & -.33 & .016 & -.27 & .043 & -.22 & .100 & .21 & .115 & .12 & .377 \\
\hline Low Well-being & -.01 & .988 & -.11 & .351 & .07 & .563 & -.07 & .550 & -.23 & .052 & -.11 & .340 & -.04 & .723 \\
\hline
\end{tabular}




\section{Table S6}

Pearson Correlations between Self-defining Memory (SDM) and SNAP Variables $(\mathrm{N}=120)$

\begin{tabular}{|c|c|c|c|c|c|c|c|c|c|c|c|c|}
\hline \multirow{2}{*}{\multicolumn{2}{|c|}{$\begin{array}{l}\text { SDM variables } \\
\text { SNAP variables }\end{array}$}} & \multicolumn{2}{|c|}{ Affect } & \multicolumn{2}{|c|}{ Structure } & \multirow{2}{*}{$\begin{array}{c}\text { Meaning } \\
\begin{array}{c}\text { Meaning- } \\
\text { making }\end{array}\end{array}$} & \multicolumn{2}{|c|}{$\begin{array}{c}\text { Relationship } \\
\text { Content }\end{array}$} & \multicolumn{2}{|c|}{$\begin{array}{c}\text { Achievement } \\
\text { Content }\end{array}$} & \multicolumn{2}{|c|}{ Theme } \\
\hline & & Positive & Negative & Specific & $\begin{array}{l}\text { Specific } \\
\text { positive }\end{array}$ & & Improved & Worsened & Success & Failure & $\begin{array}{l}\text { Redemp- } \\
\text { tion }\end{array}$ & $\begin{array}{c}\text { Contam- } \\
\text { ination }\end{array}$ \\
\hline Positive Temperament & $r$ & .17 & -.05 & -.12 & .05 & .22 & .10 & -.05 & .26 & -.09 & -.07 & -.08 \\
\hline & $p$ & .035 & .293 & .099 & .297 & $.008^{*}$ & .152 & .285 & $.003 *$ & .177 & .239 & .187 \\
\hline $95 \%$ b.c. C.I. & & $\begin{array}{r}{[-.03-} \\
.36]\end{array}$ & $\begin{array}{r}{[-.24-} \\
.16]\end{array}$ & $\begin{array}{r}{[-.25-} \\
.14]\end{array}$ & $\begin{array}{r}{[-.12-} \\
.21]\end{array}$ & $\begin{array}{r}{[.05-} \\
.35]\end{array}$ & $\begin{array}{r}{[-.02-} \\
.33]\end{array}$ & $\begin{array}{r}{[-.13-} \\
.23]\end{array}$ & $\begin{array}{r}{[.04-} \\
.36]\end{array}$ & $\begin{array}{r}{[-.12-} \\
.23]\end{array}$ & $\begin{array}{r}{[-.22-} \\
.14]\end{array}$ & $\begin{array}{r}{[-.25-} \\
.10]\end{array}$ \\
\hline Neg. Temperament & $r$ & -.16 & .17 & -.02 & -.06 & -.21 & .01 & .17 & -.25 & .06 & -.08 & .17 \\
\hline & $p$ & .038 & .032 & .417 & .272 & .012 & .473 & .034 & $.003^{*}$ & .279 & .209 & .037 \\
\hline $95 \%$ b.c. C.I. & & $\begin{array}{r}{[-.33-} \\
.01]\end{array}$ & $\begin{array}{r}{[.02-} \\
.31]\end{array}$ & $\begin{array}{r}{[-.10-} \\
.26]\end{array}$ & $\begin{array}{r}{[-.25-} \\
.16]\end{array}$ & $\begin{array}{r}{[-.28-} \\
.11]\end{array}$ & $\begin{array}{r}{[-.25-} \\
.10]\end{array}$ & $\begin{array}{r}{[-.14-} \\
.18]\end{array}$ & $\begin{array}{r}{[-.27-} \\
.10]\end{array}$ & $\begin{array}{r}{[-.23-} \\
.13]\end{array}$ & $\begin{array}{r}{[-.20-} \\
.18]\end{array}$ & $\begin{array}{r}{[-.05-} \\
.36]\end{array}$ \\
\hline Disinhibition & $r$ & .05 & -.04 & -.14 & .04 & -.13 & .04 & -.13 & -.07 & .10 & -.07 & -.13 \\
\hline & $p$ & .293 & .349 & .048 & .341 & .062 & .307 & .063 & .189 & .109 & .203 & .054 \\
\hline $95 \%$ b.c. C.I. & & $\begin{array}{r}{[-.10-} \\
.22]\end{array}$ & $\begin{array}{r}{[-.20-} \\
.15]\end{array}$ & $\begin{array}{r}{[-.37-} \\
.12]\end{array}$ & $\begin{array}{r}{[-.16-} \\
.24]\end{array}$ & $\begin{array}{r}{[-.29-} \\
.05]\end{array}$ & $\begin{array}{r}{[-.13-} \\
.16]\end{array}$ & $\begin{array}{r}{[-.21-} \\
.14]\end{array}$ & $\begin{array}{r}{[-.32-} \\
.07]\end{array}$ & $\begin{array}{r}{[-.10-} \\
.31]\end{array}$ & $\begin{array}{r}{[-.21-} \\
.15]\end{array}$ & $\begin{array}{r}{[-.21-} \\
.18]\end{array}$ \\
\hline Detachment & $r$ & -.24 & -.06 & .14 & -.01 & -.22 & -.25 & -.11 & -.24 & .00 & -.13 & .06 \\
\hline & $p$ & $.004^{*}$ & .259 & .068 & .456 & $.007^{*}$ & $.002 *$ & .125 & $.004 *$ & .491 & .074 & .253 \\
\hline $95 \%$ b.c. C.I. & & $\begin{array}{r}{[-.38-} \\
-.02]\end{array}$ & $\begin{array}{r}{[-.20-} \\
.11]\end{array}$ & $\begin{array}{r}{[-.03-} \\
.33]\end{array}$ & $\begin{array}{r}{[-.20-} \\
.19]\end{array}$ & $\begin{array}{r}{[-.39-} \\
-.05]\end{array}$ & $\begin{array}{r}{[-.39-} \\
-.04]\end{array}$ & $\begin{array}{r}{[-.31-} \\
.08]\end{array}$ & $\begin{array}{r}{[-.38-} \\
-.08]\end{array}$ & $\begin{array}{r}{[-.17-} \\
.21]\end{array}$ & $\begin{array}{r}{[-.30-} \\
-.01]\end{array}$ & $\begin{array}{r}{[-.08-} \\
.21]\end{array}$ \\
\hline
\end{tabular}

Notes: Correlations significant at $\alpha<.05$ are bolded; ${ }^{*} p<.01 ;{ }^{\dagger}<.001$ (one-tailed). Shaded are tests corresponding to specific hypotheses. SNAP: Schedule of Nonadaptive and Adaptive Personality. Bootstrapping estimates of 95\% bias-corrected C.I.s based on 1000 iterations. (For small-to-medium bivariate correlations (in EAs in the Supplementary Materials), NHT power at $N=120-133$ was $.72-.76$ for $r=.20$ and $.96-.98$ for $r=.30$.) 


\section{Table S7}

Pearson Correlations between Self-defining Memory (SDM) and NEO-FFI Variables ( $\mathrm{N}=120)$

\begin{tabular}{|c|c|c|c|c|c|c|c|c|c|c|c|c|}
\hline \multirow{2}{*}{$\begin{array}{c}\text { SDM variables } \\
\text { NEO-FFI variables }\end{array}$} & \multicolumn{3}{|c|}{ Affect } & \multicolumn{2}{|c|}{ Structure } & \multirow{2}{*}{$\begin{array}{c}\text { Meaning } \\
\begin{array}{c}\text { Meaning- } \\
\text { making }\end{array}\end{array}$} & \multicolumn{2}{|c|}{$\begin{array}{c}\text { Relationship } \\
\text { Content }\end{array}$} & \multicolumn{2}{|c|}{$\begin{array}{c}\text { Achievement } \\
\text { Content }\end{array}$} & \multicolumn{2}{|c|}{ Theme } \\
\hline & & Positive & Negative & Specific & $\begin{array}{l}\text { Specific } \\
\text { positive }\end{array}$ & & Improved & Worsened & Success & Failure & $\begin{array}{l}\text { Redemp- } \\
\text { tion }\end{array}$ & $\begin{array}{c}\text { Contam- } \\
\text { ination } \\
\end{array}$ \\
\hline \multirow[t]{2}{*}{ Openness } & $r$ & .06 & .08 & .19 & .10 & -.02 & .03 & .09 & -.06 & -.05 & -.02 & -.14 \\
\hline & $p$ & .260 & .204 & .018 & .131 & .415 & .362 & .160 & .265 & .297 & .398 & .061 \\
\hline $95 \%$ b.c. C.I. & & $\begin{array}{r}{[-.14-} \\
.24]\end{array}$ & $\begin{array}{r}{[-.09-} \\
.23]\end{array}$ & $\begin{array}{r}{[01-} \\
.34]\end{array}$ & $\begin{array}{r}{[-.07-} \\
.27]\end{array}$ & $\begin{array}{r}{[-.21-} \\
.16]\end{array}$ & $\begin{array}{r}{[-.16-} \\
.18]\end{array}$ & $\begin{array}{r}{[-.10-} \\
.27]\end{array}$ & $\begin{array}{r}{[-.25-} \\
.11]\end{array}$ & $\begin{array}{r}{[-.22-} \\
.13]\end{array}$ & $\begin{array}{r}{[-.20-} \\
.15]\end{array}$ & $\begin{array}{r}{[-.32-} \\
.06]\end{array}$ \\
\hline \multirow[t]{2}{*}{ Agreeableness } & $r$ & .06 & .04 & .06 & .04 & .26 & .13 & .04 & .13 & -.06 & .04 & -.05 \\
\hline & $p$ & .260 & .330 & .274 & .336 & $.002^{*}$ & .079 & .332 & .076 & .247 & .325 & .285 \\
\hline 95\% b.c. C.I. & & $\begin{array}{r}{[-.14-} \\
.22]\end{array}$ & $\begin{array}{r}{[-.13-} \\
.18]\end{array}$ & $\begin{array}{r}{[-.17-} \\
.23]\end{array}$ & $\begin{array}{r}{[-.13-} \\
.24]\end{array}$ & $\begin{array}{r}{[.08-} \\
.42]\end{array}$ & $\begin{array}{r}{[-.07-} \\
.29]\end{array}$ & $\begin{array}{r}{[-.14-} \\
.21]\end{array}$ & $\begin{array}{r}{[-.04-} \\
.28]\end{array}$ & $\begin{array}{r}{[-.24-} \\
.09]\end{array}$ & $\begin{array}{r}{[-.12-} \\
.21]\end{array}$ & $\begin{array}{r}{[-.25-} \\
.13]\end{array}$ \\
\hline \multirow[t]{2}{*}{ Extraversion } & $r$ & .32 & .01 & -.14 & .10 & .20 & .10 & -.03 & .27 & -.03 & .01 & -.14 \\
\hline & $p$ & $<.001^{\dagger}$ & .493 & .058 & .150 & .014 & .142 & .391 & $.002^{*}$ & .381 & .446 & .058 \\
\hline 95\% b.c. C.I. & & $\begin{array}{r}{[.13-} \\
.49]\end{array}$ & $\begin{array}{r}{[-.21-} \\
.19]\end{array}$ & $\begin{array}{r}{[-.33-} \\
.03]\end{array}$ & $\begin{array}{r}{[-.08-} \\
.27]\end{array}$ & $\begin{array}{r}{[.02-} \\
.37]\end{array}$ & $\begin{array}{r}{[-.11-} \\
.25]\end{array}$ & $\begin{array}{r}{[-.19-} \\
.14]\end{array}$ & $\begin{array}{r}{[.10-} \\
.42]\end{array}$ & $\begin{array}{r}{[-.19-} \\
.12]\end{array}$ & $\begin{array}{r}{[-.19-} \\
.23]\end{array}$ & $\begin{array}{r}{[-.30-} \\
-.01]\end{array}$ \\
\hline \multirow[t]{2}{*}{ Neuroticism } & $r$ & -.17 & .29 & .04 & -.16 & -.14 & -.04 & .15 & -.14 & .10 & -.08 & .18 \\
\hline & $p$ & .034 & $.001 *$ & .345 & .045 & .060 & .316 & .053 & .062 & .142 & .201 & .022 \\
\hline $95 \%$ b.c. C.I. & & $\begin{array}{r}{[-.33-} \\
.02]\end{array}$ & $\begin{array}{r}{[.16-} \\
.43]\end{array}$ & $\begin{array}{r}{[-.11-} \\
.19]\end{array}$ & $\begin{array}{r}{[-.32-} \\
.01]\end{array}$ & $\begin{array}{r}{[-.33-} \\
.04]\end{array}$ & $\begin{array}{r}{[-.23-} \\
.16]\end{array}$ & $\begin{array}{r}{[-.05-} \\
.35]\end{array}$ & $\begin{array}{r}{[-.30-} \\
.03]\end{array}$ & $\begin{array}{r}{[-.10-} \\
.30]\end{array}$ & $\begin{array}{r}{[-.28-} \\
.14]\end{array}$ & $\begin{array}{r}{[-.02-} \\
.38]\end{array}$ \\
\hline \multirow[t]{2}{*}{ Conscientiousness } & $\boldsymbol{r}$ & -.11 & .09 & .23 & -.02 & .06 & -.05 & .00 & .11 & -.18 & -.03 & .13 \\
\hline & $p$ & .108 & .169 & $.005^{*}$ & .412 & .276 & .300 & .496 & .123 & .025 & .386 & .073 \\
\hline 95\% b.c. C.I. & & $\begin{array}{r}{[-.28-} \\
.06]\end{array}$ & $\begin{array}{r}{[-.07-} \\
.23]\end{array}$ & $\begin{array}{r}{[.04-} \\
.40]\end{array}$ & $\begin{array}{r}{[-.24-} \\
.20]\end{array}$ & $\begin{array}{r}{[-.11-} \\
.21]\end{array}$ & $\begin{array}{r}{[-.20-} \\
.10]\end{array}$ & $\begin{array}{r}{[-.16-} \\
.15]\end{array}$ & $\begin{array}{r}{[-.05-} \\
.24]\end{array}$ & $\begin{array}{r}{[-.36-} \\
-.02]\end{array}$ & $\begin{array}{r}{[-.20-} \\
.14]\end{array}$ & $\begin{array}{r}{[-.05-} \\
.29]\end{array}$ \\
\hline
\end{tabular}

Notes: Correlations significant at $\alpha<.05$ are bolded; ${ }^{*} p<.01 ;{ }^{\dagger}<.001$ (one-tailed). Shaded are tests corresponding to specific hypotheses. ${ }^{\text {AR }}$ Attempt at replication of a finding from Blagov \& Singer (2004). NEO-FFI: NEO Five-Factor Inventory. Bootstrapping estimates of $95 \%$ bias-corrected C.I.s based on 1000 iterations. (For small-to-medium bivariate correlations (in EAs in the Supplementary Materials), NHT power at $N=120-133$ was $.72-.76$ for $r=.20$ and $.96-$ .98 for $r=.30$.) 


\section{Table S8}

Pearson Correlations between Self-defining Memory (SDM) and WAI-SF Variables ( $\mathrm{N}=133)$

\begin{tabular}{|c|c|c|c|c|c|c|c|c|c|c|c|c|}
\hline \multirow{2}{*}{$\begin{array}{c}\text { SDM variables } \\
\text { WAI-SF variables }\end{array}$} & \multicolumn{3}{|c|}{ Affect } & \multicolumn{2}{|c|}{ Structure } & \multirow{2}{*}{$\begin{array}{l}\text { Meaning } \\
\text { Meaning- } \\
\text { making }\end{array}$} & \multicolumn{2}{|c|}{$\begin{array}{c}\text { Relationship } \\
\text { Content }\end{array}$} & \multicolumn{2}{|c|}{$\begin{array}{l}\text { Achievement } \\
\text { Content }\end{array}$} & \multicolumn{2}{|c|}{ Theme } \\
\hline & & Positive & Negative & Specific & $\begin{array}{l}\text { Specific } \\
\text { positive }\end{array}$ & & Improved & Worsened & Success & Failure & $\begin{array}{l}\text { Redemp- } \\
\text { tion }\end{array}$ & $\begin{array}{c}\text { Contam- } \\
\text { ination }\end{array}$ \\
\hline Distress & $r$ & $-.23^{\mathrm{AR}}$ & $.29^{\mathrm{AR}}$ & .02 & $-.24^{\mathrm{AR}}$ & -.20 & $.01^{\mathrm{AR}}$ & $.18^{\mathrm{AR}}$ & $-.19^{\mathrm{AR}}$ & $.12^{\mathrm{AR}}$ & -.10 & .19 \\
\hline & $p$ & $.004^{*}$ & $<.001^{\dagger}$ & .424 & $.003^{*}$ & .010 & .481 & .018 & .015 & .085 & .123 & .013 \\
\hline $95 \%$ b.c. C.I. & & $\begin{array}{r}{[-.37-} \\
-.06]\end{array}$ & $\begin{array}{r}{[.15-} \\
.42]\end{array}$ & $\begin{array}{r}{[-.09-} \\
.23]\end{array}$ & $\begin{array}{r}{[-.35-} \\
-.04]\end{array}$ & $\begin{array}{r}{[-.40-} \\
-.01]\end{array}$ & $\begin{array}{r}{[-.21-} \\
.16]\end{array}$ & $\begin{array}{r}{[.01-} \\
.39]\end{array}$ & $\begin{array}{r}{[-.35-} \\
-.02]\end{array}$ & $\begin{array}{r}{[-.06-} \\
.31]\end{array}$ & $\begin{array}{r}{[-.29-} \\
.14]\end{array}$ & $\begin{array}{r}{[.02-} \\
.36]\end{array}$ \\
\hline Self-restraint & $r$ & -.04 & .02 & .29 & .12 & $.17^{\S}$ & .01 & -.04 & .06 & -.18 & .08 & .02 \\
\hline & $p$ & .340 & .423 & $<.001^{\dagger}$ & .095 & .027 & .445 & .310 & .245 & .019 & .181 & .390 \\
\hline $95 \%$ b.c. C.I. & & $\begin{array}{r}{[-.25-} \\
.11]\end{array}$ & $\begin{array}{r}{[-.17-} \\
.13]\end{array}$ & $\begin{array}{r}{[.09-} \\
.48]\end{array}$ & $\begin{array}{r}{[-.06-} \\
.32]\end{array}$ & $\begin{array}{r}{[-.03-} \\
.29]\end{array}$ & $\begin{array}{r}{[-.11-} \\
.16]\end{array}$ & $\begin{array}{r}{[-.22-} \\
.08]\end{array}$ & $\begin{array}{r}{[-.15-} \\
.20]\end{array}$ & $\begin{array}{r}{[-.37-} \\
-.02]\end{array}$ & $\begin{array}{r}{[-.16-} \\
.21]\end{array}$ & $\begin{array}{r}{[-.22-} \\
.17]\end{array}$ \\
\hline Repressive & $r$ & .08 & .04 & .07 & $.08^{\mathrm{AR}}$ & .12 & .03 & -.04 & .06 & -.11 & .12 & -.12 \\
\hline Defensiveness & $p$ & .195 & .33 & .208 & .168 & .089 & .366 & .329 & .253 & .102 & .083 & .078 \\
\hline 95\% b.c. C.I. & & $\begin{array}{r}{[-.13-} \\
.26]\end{array}$ & $\begin{array}{r}{[-.16-} \\
.16]\end{array}$ & $\begin{array}{r}{[-.09-} \\
.20]\end{array}$ & $\begin{array}{r}{[-.11-} \\
.28]\end{array}$ & $\begin{array}{r}{[-.11-} \\
.29]\end{array}$ & $\begin{array}{r}{[-.16-} \\
.25]\end{array}$ & $\begin{array}{r}{[-.22-} \\
.11]\end{array}$ & $\begin{array}{r}{[-.10-} \\
.23]\end{array}$ & $\begin{array}{r}{[-.24-} \\
.04]\end{array}$ & $\begin{array}{r}{[-.11-} \\
.30]\end{array}$ & $\begin{array}{r}{[-.32-} \\
.01]\end{array}$ \\
\hline
\end{tabular}

Notes: Correlations significant at $\alpha<.05$ are bolded; ${ }^{*} p<.01 ;{ }^{\dagger}<.001$ (one-tailed). Shaded are tests corresponding to specific hypotheses. ${ }^{\text {AR }}$ Attempt at replication. WAI-SF: Weinberger Adjustment Inventory - Short Form. Bootstrapping estimates of $95 \%$ bias-corrected C.I.s based on 1000 iterations. ${ }^{\S}$ The quadratic term for Self-restraint was non-significant. (For small-to-medium bivariate correlations (in EAs in the Supplementary Materials), NHT power at $N=$ $120-133$ was $.72-.76$ for $r=.20$ and $.96-.98$ for $r=.30$.) 


\section{Table S9}

Inter-rater Reliability of Coding at Times 1, 2, and 3

\section{Cohen's к}

\begin{tabular}{lcccc}
\hline Narrative Characteristics & Time 1 & Time 2 & Time 3 & Mean \\
\hline Memories coded & 100 & 50 & 50 & 67 \\
\hline $\begin{array}{l}\text { Structure } \\
\quad \text { Specific vs. non-specific }\end{array}$ & .83 & .75 & .78 & 0.79 \\
$\begin{array}{l}\text { Meaning Making } \\
\quad \text { Present vs. absent }\end{array}$ & .79 & .79 & .86 & 0.81 \\
Thematic content & & & & \\
$\quad$ Relationship - Improved & .72 & .58 & .69 & 0.66 \\
$\quad$ Relationship - Worsened & .77 & .69 & .75 & 0.74 \\
$\quad$ Achievement - Success & .81 & .77 & .83 & 0.80 \\
$\quad$ Achievement - Failure & .69 & .73 & .72 & 0.71 \\
$\quad$ Contamination (present vs. absent) & .76 & .67 & .80 & 0.74 \\
$\quad$ Redemption (present vs. absent) & .75 & .66 & .73 & 0.71 \\
\hline
\end{tabular}




\section{Table S10}

Multilevel Modeling Results for SDM Variables and Big Three Superfactors

\begin{tabular}{|c|c|c|c|c|c|}
\hline Positive Emotionality $^{1}$ & Est. & SE & $95 \% \mathrm{CI}$ & $p$ & \\
\hline Positive Affect in SDMs & 0.26 & 0.049 & $0.13-0.32$ & $<.001$ & \\
\hline Negative Affect in SDMs & -0.002 & .037 & $-0.07-0.07$ & .960 & \\
\hline Specific SDMs & -0.03 & .027 & $-0.04-0.003$ & .027 & \\
\hline Specific positive SDMs & $<-0.001$ & 0.015 & $-0.03-0.03$ & .997 & \\
\hline SDMs & 0.21 & 0.009 & $0.19-0.23$ & $<.001$ & \\
\hline proved & 0.03 & 0.010 & $0.01-0.04$ & .011 & \\
\hline Jorsened & 0.01 & 0.009 & $-0.01-0.02$ & .489 & \\
\hline ment - Success & 0.06 & 0.014 & $0.03-0.08$ & $<.001$ & \\
\hline nent - Failure & $<-0.001$ & 0.009 & $-0.02-0.02$ & .985 & \\
\hline Con & -0.02 & 0.010 & $-0.04-0.001$ & .068 & \\
\hline Red & 0.01 & 0.008 & $-0.01-0.02$ & .522 & \\
\hline Negative Em & Est. & SE & $95 \% \mathrm{CI}$ & $p$ & \\
\hline & & & $-0.28--0.08$ & & \\
\hline Affect in SDMs & 0.20 & 0.037 & $0.12-0.27$ & $<.001$ & \\
\hline SDMs & 0.01 & 0.011 & $-0.01-0.03$ & .299 & \\
\hline & -0.0 & 0.015 & $(-0.07-0.01)$ & .016 & \\
\hline DMs & -0.04 & 0.014 & $-0.07--0.014$ & .003 & \\
\hline roved & -0.01 & & $-0.03-0.01$ & .468 & \\
\hline rsened & 0.02 & 0.010 & $-0.001-0.03$ & .097 & \\
\hline & -0.03 & & $-0.06--0.01$ & .013 & \\
\hline & 0.01 & 0.009 & $-0.01-0.03$ & .327 & \\
\hline & & & & .002 & \\
\hline & -0.01 & 0.009 & $-0.02-0.01$ & .463 & \\
\hline Con & Est. & SE & $95 \%$ CI & $p$ & \\
\hline & & & $-0.20--0.01$ & & \\
\hline & & & & & \\
\hline $\mathrm{Sp}$ & & 0.011 & $0.03-0.07$ & $<.001$ & \\
\hline & & & $(-0.02-0.04)$ & .537 & \\
\hline SDMs & & 0.012 & $0.004-0.05$ & .019 & \\
\hline & & & $-0.03-0.01$ & .461 & \\
\hline hip - Worsened & -0.001 & 0.009 & $-0.02-0.02$ & .829 & \\
\hline & & & $-0.004-0.05$ & .101 & \\
\hline nent - Failure & -0.02 & & $-0.04-0.003$ & .018 & \\
\hline & & 0.010 & $-0.001-0.04$ & .044 & \\
\hline Redemption & $<0.001$ & 0.007 & $-0.01-0.01$ & .996 & \\
\hline
\end{tabular}

Note: REML estimation with $95 \%$ bias-corrected CI bootstrapping with 1000 iterations. ${ }^{*} p<.05$ (two-tailed). (All null-model tests had $p$ s $<.001$.) 10 SDMs per 120 participants. ${ }^{1}$ Based on SNAP Positive Temperament, SNAP Detachment, and NEO-FFI Extraversion. ${ }^{2}$ Based on SNAP Negative Temperament, NEO-FFI Neuroticism, and WAI-SF Distress. ${ }^{3}$ Based on SNAP Disinhibition, NEO-FFI Conscientiousness, and WAI-SF Self-restraint. Each superfactor was derived using regression-based factor scores from a single-component extraction in a principal components analysis of the respective SNAP, NEO-FFI, and WAI-SF scales. 


\section{Table S11}

Principal Components Analysis of Personality Dimensions for Data Reduction Purposes: An Extraction of Three Components with Varimax Rotation $(\mathrm{N}=122)$

\begin{tabular}{|c|c|c|c|c|c|c|c|}
\hline \multirow{2}{*}{$\begin{array}{l}\text { Personality } \\
\text { dimension }\end{array}$} & \multicolumn{3}{|c|}{ Component } & \multicolumn{3}{|c|}{ Variance Explained } & \multirow{2}{*}{$\begin{array}{c}\text { Commu- } \\
\text { nality }\end{array}$} \\
\hline & NEM & PEM & $\mathrm{CON}$ & \# & Eigenvalue & $\%$ & \\
\hline WAI-SF Distress & .88 & & & 1 & 3.6 & 40 & .87 \\
\hline NEO-FFI Neuroticism & .88 & & & 2 & 1.8 & 21 & .83 \\
\hline SNAP Negative Temperament & .80 & & & 3 & 1.3 & 14 & .65 \\
\hline SNAP Detachment & & -.88 & & & & & .78 \\
\hline NEO-FFI Extraversion & -.33 & .85 & & & & & .83 \\
\hline SNAP Positive Temperament & & .81 & & & & & .69 \\
\hline SNAP Disinhibition & & & -.83 & & & & .70 \\
\hline NEO-FFI Conscientiousness & & & .79 & & & & .67 \\
\hline WAI-SF Self-restraint & & & .78 & & & & .67 \\
\hline
\end{tabular}

Note: Loadings > .3 were omitted. PEM: Positive Emotionality; NEM: Negative Emotionality; CON: Constraint. SNAP: Schedule for Nonadaptive and Adaptive Personality; NEO-FFI: NEO Five-Factor Inventory; WAI-SF: Weinberger Adjustment Inventory - Short Form. 


\section{Table S12}

A Comparison of Demographic, Narrative, and Personality Variables between the Old 2004 Study (Sample 1, $N=103$ ) and the Current Study (Sample 2, $N=133$ )

\begin{tabular}{|c|c|c|c|c|c|c|c|}
\hline Dependent Variables & $t_{W}{ }^{1}$ & $p$ & $M_{\text {Sample 1 }}$ & $(S D)$ & & $M_{\text {Sample } 2}$ & $(S D)$ \\
\hline Sex (men) & 0.10 & .918 & $23 \%$ & $(0.425)$ & & $23 \%$ & $(0.421)$ \\
\hline Age (years) & -6.55 & $<.001 *$ & 18.8 & $(0.941)$ & & 19.8 & $(1.356)$ \\
\hline Specific SDMs & -2.86 & .005 & 7.8 & $(2.053)$ & $<$ & 8.5 & $(1.617)$ \\
\hline Meaning-making SDMs & 0.11 & .917 & 2.9 & $(2.836)$ & $\approx$ & 2.9 & $(2.553)$ \\
\hline Undisrupted Relationships 2 & 0.27 & .785 & 1.5 & $(1.558)$ & $\approx$ & 1.5 & $(1.352)$ \\
\hline Worsened Relationships & 3.00 & $.003 *$ & 1.5 & $(1.349)$ & $>$ & 1.1 & $(1.057)$ \\
\hline Achievement Success & -3.15 & .002 & 2.3 & $(1.631)$ & $<$ & 3.0 & $(2.047)$ \\
\hline Achievement Failure & -6.78 & $<.001$ & 0.3 & $(0.666)$ & $<$ & 1.1 & $(1.081)$ \\
\hline WAI-SF Distress & -0.52 & .602 & 2.67 & $(0.784)$ & $\approx$ & 2.72 & $(0.714)$ \\
\hline WAI-SF Self-restraint & -0.43 & .665 & 4.11 & $(0.459)$ & $\approx$ & 4.14 & $(0.539)$ \\
\hline WAI-SF Defensiveness & -2.63 & $.009 *$ & 2.38 & $(0.566)$ & $<$ & 2.58 & $(0.602)$ \\
\hline
\end{tabular}
${ }^{*} p<.05$ (two-tailed).

1 Welch's $t$ test (equal variances not assumed).

2 This variable was operationalized somewhat differently between the two studies (as undisrupted relationships in the older study and improved relationships in the current one). 


\section{Figure S1}

An Alternative Visualization of the Interaction (to Figure 1 in the Manuscript). The Tendency to Recall Meaning-making Self-Defining Memories (Low $\leq 2$, High > 2) Moderates the Relationship Between Memory Affect and WAI-SF Distress Scores.

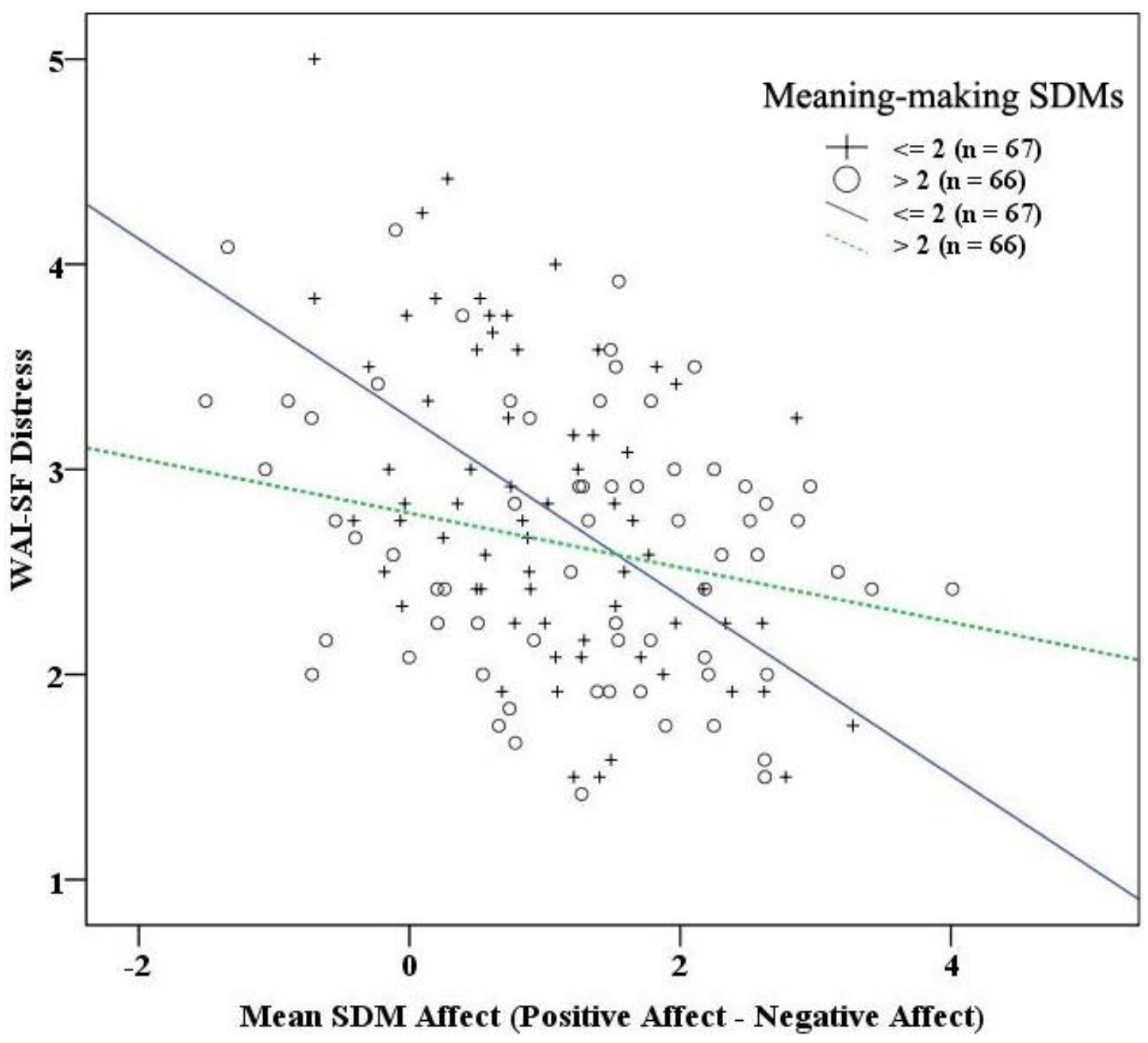




\section{Figure S2}

A Visualization of the Hypotheses and Findings Linking Narrative Features of Self-defining Memories (SDMs) and Personality

\section{Dimensions}

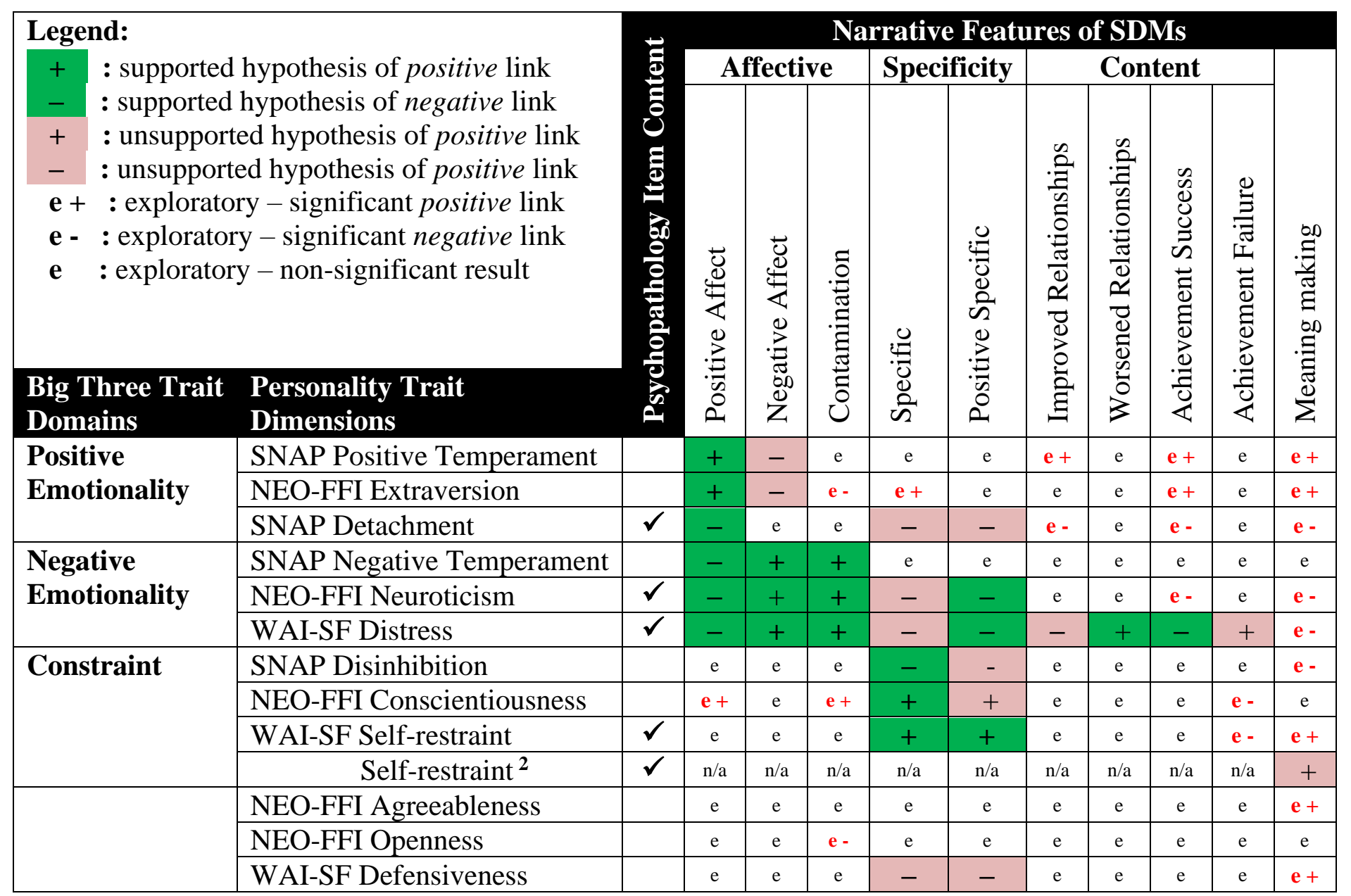




\section{Figure S3}

Outcomes from the Replication Attempt: A Side-by-Side Presentation of Corresponding Findings from the Original (Blagov \& Singer, 2004) and the Current Studies

\section{SDM Variables}

Positive Affect

Negative Affect

Specific

Specific Positive

Meaning-making

Improved Relationship

Worsened Relationship

Achievement Success

Achievement Failure

\section{WAI-SF Variables 2004 Hypothesis 2004 Finding} $r<0$

$r>0$ Distress

Distress

Defensiveness

Distress

Self-restraint

Self-restraint

Distress

Distress

Distress

Distress $r<0$

$r<0$

$r<0$

Quadratic ${ }^{1}$

$-$

$r<0$

$r>0$

$r<0$

$r>0$

\section{$r=.52, p<.001$}

$r=-.18, p<.10$

$r=.006, N S$

$r=-.22, p<.05$

$r=-.32, p<.001$

$F=4.02, p=.021$

-

$r=-.11, N S$

$r=.33, p<.001$

$r=-.24, p<.05$

$r=-.05, N S$

\section{Current Finding Outcome}

Est. $=-0.84, \mathrm{p}<.001$ Successful replication

Est. $=0.28, p<.001 \quad$ Successful replication

Est. $=0.004, p=.411$ Consistent NS results

Est. $=0.02, p=.125 \quad$ Failed replication

Est. $=-0.07, p<.001$ Successful replication

Est. $=-0.15, p=.216$ Failed replication

Est. $=0.07, p=.008$ Partially consistent pattern ${ }^{2}$

Est. $=0.01, p=.464$ Consistent NS results

Est. $=0.03, p=.018$ Successful replication

Est $=-0.05, p=.001$ Successful replication

Est $=0.02, p=.051 \quad$ Consistent $N S$ results

Note: SDM - self-defining memory; WAI-SF - Weinberger Adjustment Inventory - Short Form; 2004 - Blagov and Singer (2004); NS non-significant.

Note: Outcomes are color-coded as follows: Successful replications in green; consistent non-significant results and one partially consistent pattern in yellow; and failed replications in purple.

Note: See the manuscript, Table 2, for bootstrapped confidence intervals from the current study and other detail.

${ }^{1}$ Precited the highest number of meaning-making SDMs in participants with moderate, followed by high, followed by low Self-restraint.

${ }^{2}$ In both the 2004 and the current studies, participants lowest on Self-restraint yielded the lowest numbers of meaning-making SDMs. 
Intentionally Blank 